\title{
Cooking Traces on Copper Age Pottery from Central Italy: an Integrated Approach comprising Use Wear Analysis, Spectroscopic Analysis and Experimental Archaeology
}

\author{
Vanessa Forte $^{1^{*}}$, Stella Nunziante Cesaro ${ }^{2}$, Laura Medeghini ${ }^{3}$ \\ ${ }^{1}$ McDonald Institute for Archaeological Research, University of Cambridge, Downing Street, CB2 3EF \\ Cambridge, United Kingdom/Laboratory of Technological and Functional Analyses of Prehistoric Artefacts \\ (LTFAPA), Sapienza University of Rome, P.le A. Moro 5, 00185 Rome, Italy; vf261@ cam.ac.uk \\ ${ }^{2}$ Scientific Methodologies Applied to Cultural Heritage (SMATCH), ISMN-CNR, Sapienza University of \\ Rome, P.le A. Moro 5, 00185 Rome, Italy; stella.nunziante@libero.it \\ ${ }^{3}$ Department of Earth Sciences, Sapienza University of Rome, P.le A. Moro 5, 00185 Rome, Italy \\ laura.medeghini@uniroma1.it
}

\begin{abstract}
This contribution discusses the results of an integrated approach of use wear analysis, spectroscopic analysis and experimental archaeology, applied for the investigation of the actual use of selected ceramic vessels, taken from domestic Copper Age contexts in the modern Rome area.

This study is based upon the consideration of a vessel as a tool, used during everyday life and thus reflecting human activities and social behaviours. To this end, the paper here presented proposes an interpretation of the actual use activities which led to the modification of prehistoric vessels. The methodology of this study integrates the traditional approach to ceramic use wear studies, based on experimental and ethnoarchaeological studies, with principles of tribology, along with the application of a dedicated experimental framework which enabled the development of a detailed collection of comparative use wear. Moreover, the application of spectroscopic analysis provided preliminary data related to the charred encrustations found inside the archaeological specimens. These data, when combined with use wear, palaeobotanical remains and archaeological preserved structures, aided interpretation of the archaeological ceramic vessels as cooking pots.
\end{abstract}

Key words: use-wear, tribology, experimental archaeology, spectroscopic analysis, prehistoric pottery, cooking pots, copper age.

\section{Introduction}

Ceramic materials, especially in the form of pottery vessels, represent one of the most recurrent pieces of evidence related to everyday human life found in archaeological contexts.

The appearance of this technology is associated with important changes in the economy and social life of prehistoric communities (Barnett and Hoopes, 1995; Matson, 1965; Rice, 1999; Robb 2007; Sassaman, 1993; Vitelli, 1989). Consequently, its growing presence in the everyday life of prehistoric groups enables a large variety of inferences regarding its use in terms of human behaviour, directly and indirectly reflecting choices of production and use. North American archaeological interpretive traditions encouraged the development of prehistoric pottery analysis from an anthropological perspective, connecting empirical analyses of ceramic materials with ethnoarchaeology. This approach led scholars to realise the importance of focusing their research on the actual use of an object in order to understand specific human behaviours, which was of paramount importance for the development of use wear analysis in ceramic studies. 
2 Use wear analysis is a method based on the study of traces left on tools during their use. The 3 lifecycle of a functional object is subject to intentional or unintentional human activities, often 4 leading to modifications of the object's original features (Marreiros et al., 2015; Semenov, 5 1964; Vaughan, 1985).

6 The first observations of use traces on ceramic vessels focused on surface modifications and/or 7 features attributed to use activities, defined as abrasions, scratches, spalling and fire traces 8 (Bradfield, 1931; Braun et al., 1967; Chernela, 1969; Matson, 1965; Perino, 1966). These forms 9 of evidence were described and localised on the objects, yet they lacked explanations of the 10 processes involved in the formation of use wear and inferences of actual human behaviour. 11 Interest in these latter aspects became more pronounced during the following decade, in 12 relation to the growing processual debate on the theoretical and epistemological approach. In 13 this period, American scholarship on ceramic use wear developed towards an anthropological investigate wear patterns as sources of information for the actual vessel function (De Garmo, 1975; Ericson et al., 1972; Fenner, 1977; Griffith, 1978; Rohn, 1971). These works represent the first attempt to apply the newly born traceological method to ceramic studies, contemporaneous to the development of use wear analysis on lithic and bone tools (Hayden, 1979; Semenov, 1964).

Currently, our knowledge concerning use traces affecting ceramic vessels relies on an archaeological, experimental and ethnoarchaeological dataset developed mainly in the 1980s and 1990s (Bray, 1982; Bruce, 1989; Hally, 1983, 1986; Lugli and Vidale, 1996; Schiffer and Skibo, 1989; Skibo and Schiffer, 1987; Skibo, 1992). According to these studies, actions involved in cooking, storing and cleaning activities can damage the vessels and generate traces on their internal and external surfaces. While a solid foundation of knowledge regarding the principal processes of use modification is available, recently the systematic applications of use wear analyses on archaeological ceramics has remained limited to specific kinds of ceramic tools (e.g. pottery sherds for scraping activities) (Lopez Varela et al., 2002; Vieugue, 2015), with few studies focused on pottery (Banducci, 2014; Dugay, 1996; Vieugué, 2014; Vieugué et al., 2008; Vuković, 2009, 2011). To this end, interpretation of archaeological use wear on pottery usually relies on the ethnoarchaeological documentation established by Skibo (1992), which relates to the domestic ceramic assemblages of the Kalingas. Skibo (1992) developed a nomenclature on the basis of direct observation of use processes in a specific context. This study still represents a solid base in the field of ceramic use wear, even though the direct application of these observations on the archaeological materials may lead to generalised interpretations. Indeed, experimental studies on ceramics (Schiffer and Skibo, 1989; Skibo and Schiffer, 1987) demonstrated that features such as the compositional characters of raw materials and the physical properties of ceramics influence the development of wear. These findings show that dedicated studies of an object's context and associated materials, along with experiments and use wear analysis, are essential in order to adequately interpret archaeological materials and investigate the techno-functional choices that characterise a given community. Although pioneering studies have defined the basic principles of ceramic alterations and the variables affecting wear processes, allowing for the distinction between use wear and postdepositional modifications, it is still difficult to define archaeologically the variety of overlapped processes or actions related to the item's use. For example, one of the most diffused and studied forms of wear on ceramic falls within the wide category of abrasive wear. These alterations, caused by a tribological system, are due to the contact, usually through sliding, of two surfaces in relative motion, which causes the detachment of materials. Currently, while we are able to identify abrasive wear on a vessel and define whether it has been more or less invasive, we are not able to precisely establish the nature of the material with which the vessel 
came in contact during its use ${ }^{1}$. Indeed, we are able to distinguish mechanical alterations (e.g. abrasive wear) from chemical ones (e.g. corrosive wear), defining them as separate processes. However, vessels are frequently involved in both mechanical and chemical processes that are usually associated with each other; for this reason, future research should focus on these interactions and the resulting wear. Moreover, systematic experimental frameworks dedicated to monitoring not just the development processes but also to documenting trace collections associated with specific variables on vessels, are still not well defined.

This kind of approach is not yet systematically applied in traceological studies on pottery. Moreover, ethnoarchaeological references primarily concern cooking vessels featuring a rounded base and which are put on the fire, often on supports, leading to specific contextdependant wear. Their use in wet cooking causes black carbonised areas on the internal base and in the band immediately above the water level (Skibo, 1992), these being the areas most exposed to the heat. This contribution aims to investigate whether the archaeological traces observed as extended internal carbonisation were only accidental, or if it is possible to directly connect them and other archaeological use wear with culinary habits or specific processed foods.

\section{Wear processes on pottery}

The term 'wear' is used herein to refer to all the modifications produced by a reduction of the surface, regardless of their mechanical or chemical nature; conversely, the word 'residue' is used for all modifications of the original ceramic surface that derived from amorphous substances, regardless of their physical nature or chemical composition. For this reason, the study of wear on pottery focuses on the way in which ceramic particles detach from the original surface. Indeed, ceramic is a mix of clay minerals and inclusions held together by chemical bonds after firing (at temperatures over $650{ }^{\circ} \mathrm{C}$ ). As distinct from metals, where minerals are melted by firing (Radivojević et al., 2010), ceramic, both pre- and post-firing, is an aggregate of grains of different shape and size, and the way in which it wears is determined by the structure of this aggregate.

Use wear and post-depositional modifications may affect pottery mechanically and chemically and in a combination of both, altering the physical bonds between particles. After a bond breaks, the matrix particles and other mineral inclusions leave the ceramic body ${ }^{2}$ and the wear morphology develops through the way in which the material detachment occurs. This concept derives from a field of engineering named tribology studying interacting surfaces in relative motion focusing on friction, lubrification and wear (Czichos, 1978; OECD, 1969).

The potentials of this approach have been applied in archaeology by Adams $(1986,2014)$ and Adams et al. (2009) in relation to the use of macro lithic tools and the main principle has also been investigated by Schiffer and Skibo (1989) during their first experiments on ceramic use wear. The application of such principles to understand surface modifications still has significant potential to analyse use traces on archaeological ceramic and to investigate their function through experiments and scientific analyses. Use wear on pottery is usually the result of tribological mechanisms such as fatigue, abrasive, corrosive and tribochemical wear (Tab. 1) affecting the original topography of pottery surfaces that can be usually flat, sinuous or uneven. (Adams, 1986; Adams et al., 2009; Skibo and Schiffer, 1987).

\footnotetext{
${ }^{1}$ A traceological investigation to identify the nature of materials interacting with ceramic has been performed by van Gijn and Hofman (2008) and by Vieugué (2015) regarding specific ceramic tools (recycled potsherds).

${ }^{2}$ Some tribological systems cause a reinvolvement of ceramic particles (Olofsson, 2011 p.12) but this phenomenon has not been yet explored in archaeological ceramic material studies.
} 
1 Fatigue wear occurs during mechanical stress, e.g. pressure or impact (Adams, 2014), and 2 produces fractures, pits (caused by the pedestalling of inclusions) (Adams et al., 2009 and 3 references therein; Skibo and Schiffer, 1987) or spall detachments.

4 Abrasive wear results from a sliding movement between two surfaces of different hardness 5 (Adams et al., 2009 and references therein; Schiffer and Skibo, 1989; Skibo, 2015). Alterations 6 on a given ceramic surface appear in the form of striations, scratches, levelling (Adams et al., 7 2009), rounding, grooves or depressions. Structural and morphological alterations of ceramic material can also be produced by chemical mechanisms, via corrosive processes that occur during contact between certain liquid or semiliquid substances and a solid surface, causing depressions or pits (Adams et al., 2009; Adams, 2014; Arthur 2002, 2003; Skibo 1992; Skibo 2015) (Tab. 1).

Corrosive wear on ceramic can develop when the surface absorbs substances due to paste porosity, causing a loss of material. This latter type of wear can be also caused by fermentation mechanisms producing "lactic acid-forming bacteria that reduce the $\mathrm{pH}$ resulting in a highly acidic substance" (Arthur, 2003; Oura et al. 1982). Such alteration generates extended superficial cracks of varying length and depth, caused by the pressure of the gas resulting from

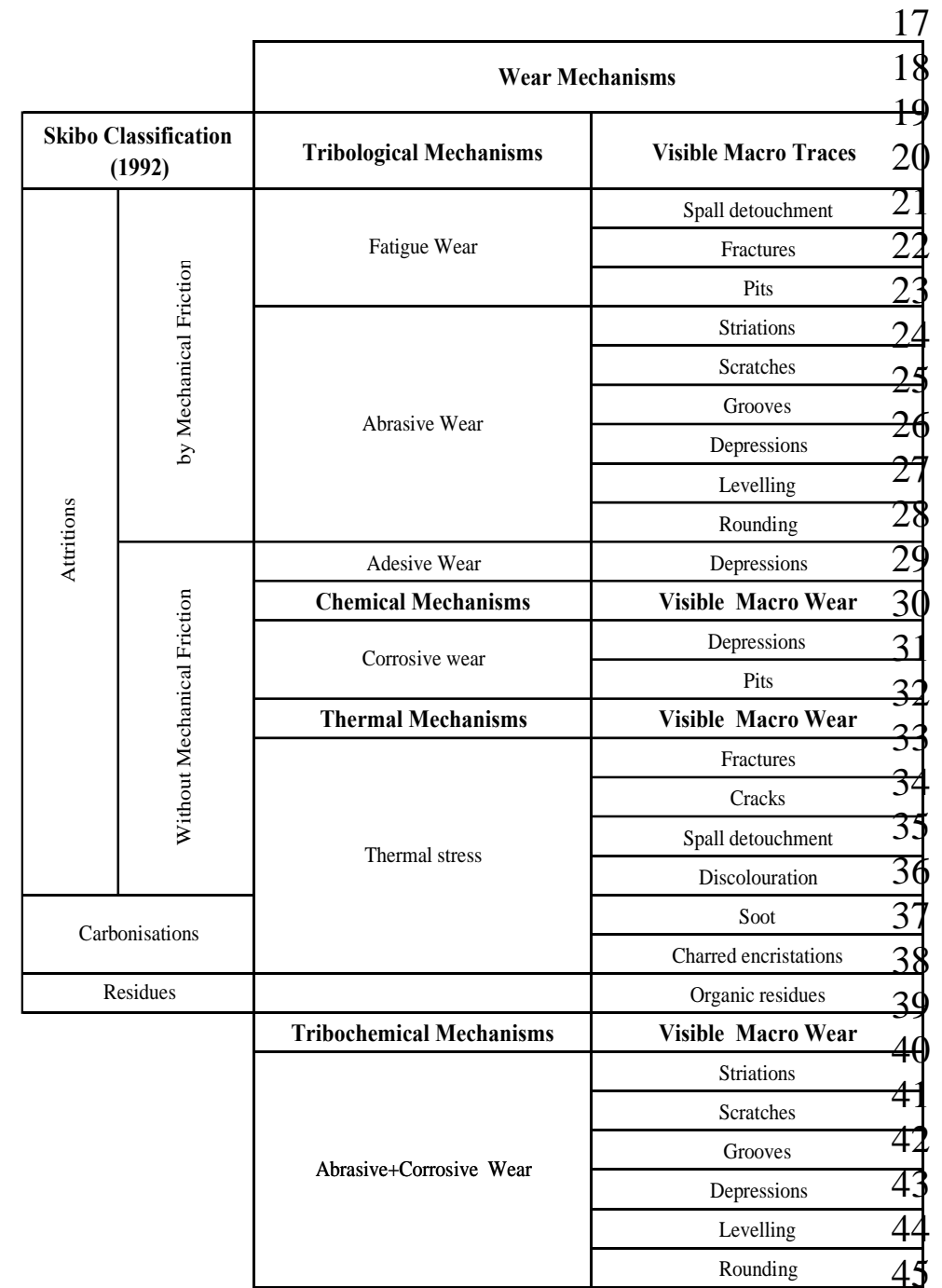

46

Table 1 - Relationships between tribological, thermal and chemical mechanisms and macro traces on pottery surfaces, considering Skibo, 48 classification $(1992,2015)$ and main wear mechanisms identified in thits article. the fermenting substances trapped in the pores (Arthur 2002, 2003). Isolated or multiple depressions can often develop due to this phenomenon. In other cases, the alteration can be caused by the acidity of mineral bonds in $\mathrm{pH}$ ranges below 4, leading to matrix dissolution (Purdy and Clark, 1987), which is visible as either a levelling or superficial depressions.

The mechanisms described above are not mutually exclusive. Generally, use alterations occur during the interaction of tribological and chemical processes, observable in the form of abrasive and corrosive wear, defined as tribochemical wear (Adams et al., 2009; Adams, 2014).

Use traces on ceramic surfaces can also result from thermal stress. Long exposure to high temperatures or thermal shocks influence the mineralogical structure of ceramics (Hally, 1983; Skibo, 1992), causing damage in the form of fractures, cracks (Adams et al., 2009) or spall 
1 detachments. They can modify the surface colour via soot concentrations (Skibo, 1992), 2 discolourations (Hally, 1983) or carbon deposits in the form of charred encrustations of food 3 (Craig, 2004; Hally, 1983; Skibo, 1992; Roffet-Salque et al., 2017) (Tab. 1).

4

\section{Material and methods}

\subsection{Sampling}

This study focuses on selected ceramic vessels coming from two Copper Age settlements of the modern Rome area in central Italy. This territory extends to the slopes of the Colli Albani volcano and was densely populated in prehistoric times. Recent excavations show an intense occupation of this area between the $4^{\text {th }}$ and $3^{\text {rd }}$ millennia BCE, testified by the presence of settlements and related burial contexts (Anzidei and Carboni, 2011; Anzidei et al., 2007, 2011; Carboni and Anzidei, 2013).

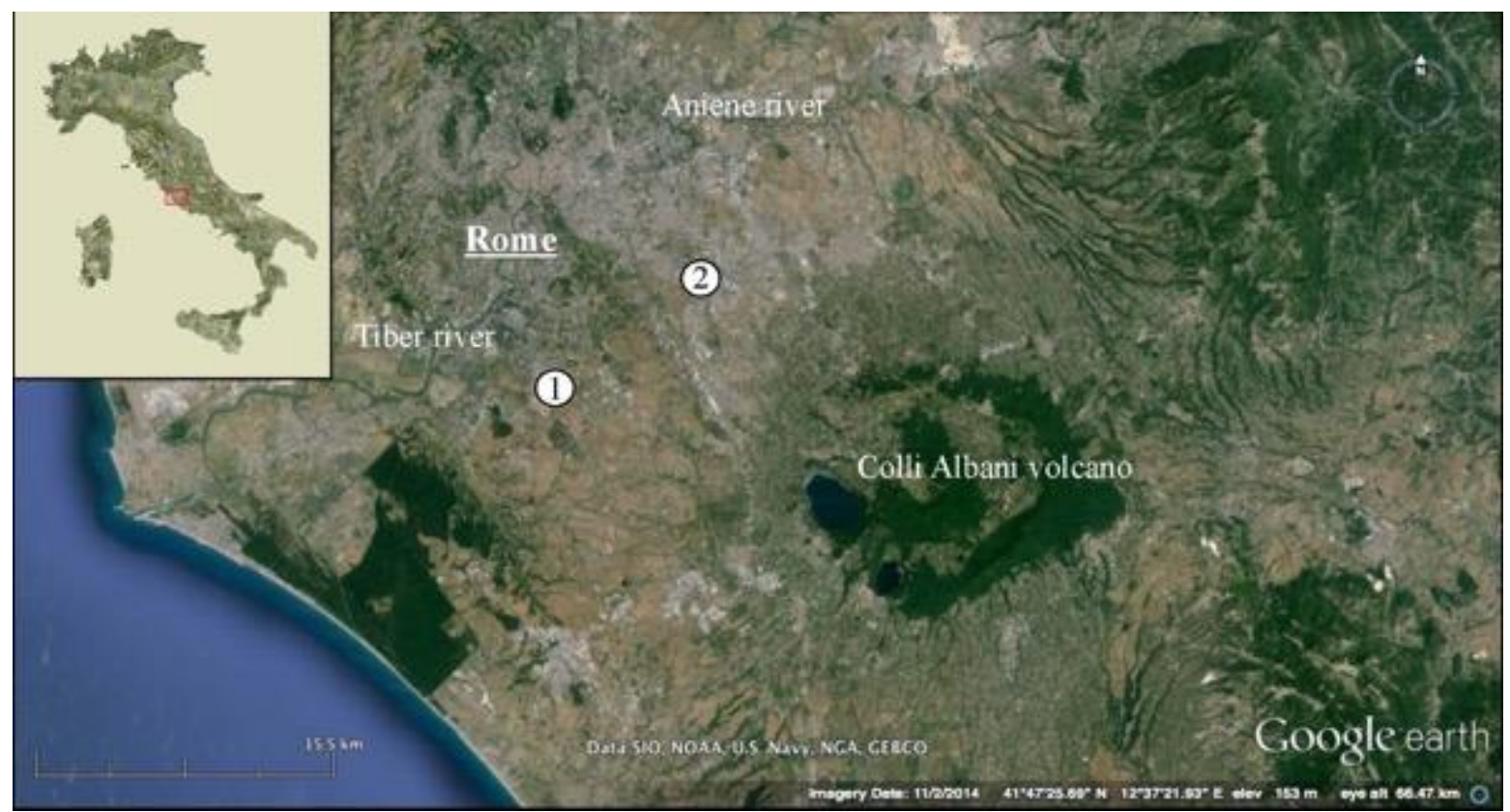

Figure 1 - Location of the Copper Age settlements of Tor Pagnotta (1) and Osteria del Curato-Via Cinquefrondi (2).

Copper Age pottery coming from the domestic contexts located in this area has been subject to an extended study of the technological and functional choices behind its production (Forte, 2015). Within this study it was possible to identify vessels featuring evident and diffused use traces; in several specimens evident charred encrustations were also observed. The recurrence of use wear and amorphous residues led to the development of a specific research framework aimed at understanding their actual use.

The ceramic vessels analysed come from the settlements of Tor Pagnotta (3090-3000 BCE and 3020-2870 BCE) (Anzidei and Carboni, 2011) and Osteria del Curato-Via Cinquefrondi (25002330 BCE and 2490-2290 BCE) (Carboni and Anzidei, 2013) (Fig. 1).

The analyses were performed on a selection of seven ceramic specimens featuring potential use traces on their internal and external surfaces (Tab.2).

Ceramic samples comprised potsherds of variable size, attributed to open vessels with a flat base (Fig. 2). An accurate technological study determined that the pottery vessels of these settlements were modelled via a coiling technique, using ceramic pastes with a semifine or coarse granulometry, and generally featuring fragments of volcanic rocks and grog (Forte and Medeghini, 2017). Morever, the external surfaces of the vessels were finished with smoothing (Rice, 1987) or burnishing (Lepère, 2014) techniques, and the firing procedure, reaching temperatures up to $850{ }^{\circ} \mathrm{C}$ (Forte and Medeghini, 2017), was performed in an oxidizing or uncontrolled atmosphere (Forte, 2015). 
1 Archaeological studies of this area, in collaboration with palaeobotanical and 2 archaeozoological specialists, detail an environment suitable for human habitation. During this 3 period the modern Rome area was characterised by mixed forests with a prevalence of

4 deciduous plants (Anzidei et al., 2007; Follieri et al., 1993; Magri and Follieri,

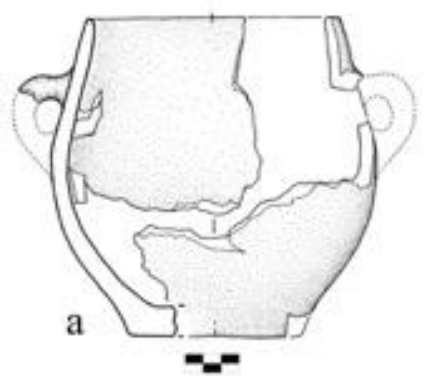
1992). Some settlements, such as Osteria del Curato-Via Cinquefrondi, were located on a fertile plain formed by lahar flows. This repeated geological event has affected the economy of prehistoric groups since the Neolithic Age, providing fertile sediments and deforested areas suited to farming (Anzidei at al., 2007). In particular,

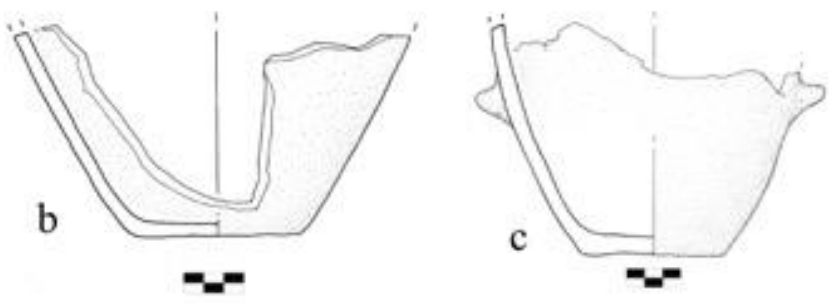
frequent remains of cereals and legumes (Anzidei et al., 2007 ), numerous ground stones and silos along with use wear on lithic tools (Lemorini, 2007) suggest their intense exploitation for domestic use (Anzidei at al., 2007). An important part of the economy was also fulfilled by animal exploitation: the
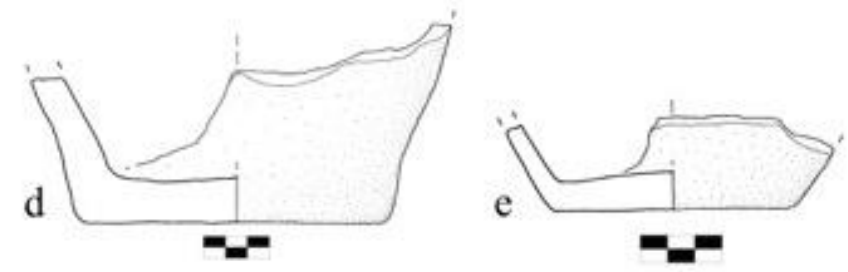

Figure 2 - Selected examples of the vessels investigated during 9 the research: a) ID 475; b) ID 138; c) ID 2; d) ID 11; e) ID 50430 analysis of animal bone remains (including goat, sheep and pig) suggested their use for meat and secondary products (Anzidei et al., 2007).

The archaeological investigation identified a clay structure from the site of Osteria del Curato-Via Cinquefrondi interpreted as an oven (Anzidei et al.,

2007). This underground structure, dated to the end of the $3^{\text {rd }}$ millennium BCE, was made in the lahar sediment, $1.20 \mathrm{~m}$ deep and $1.60 \mathrm{~m}$ wide, and featured a $25 \mathrm{~cm}$ central mud layer showing fire traces. One of the vessels considered within this research was found in relation to this structure along with botanical remains as broad bean (Vicia faba L.), animal bones and ceramic sherds (Anzidei et al., 2007). 


\begin{tabular}{|c|c|c|c|c|c|}
\hline \multirow[b]{2}{*}{ ID } & \multirow[b]{2}{*}{ Site } & \multirow[b]{2}{*}{ Chronology } & \multicolumn{2}{|c|}{ Identified use traces } & \multirow[b]{2}{*}{$\begin{array}{c}\text { Analyses } \\
\text { applied }\end{array}$} \\
\hline & & & Internal surfaces & External surfaces & \\
\hline 475 & $\mathrm{TP}$ & $\begin{array}{c}\text { late } 4^{\text {th }} / \text { early } 3^{\text {rd }} \text { millennium } \\
\text { BCE }\end{array}$ & $\begin{array}{c}\text { charred } \\
\text { encrustations }\end{array}$ & & $\begin{array}{c}\text { use wear } \\
\text { analysis + FTIR }\end{array}$ \\
\hline 469 & $\mathrm{TP}$ & $\begin{array}{c}\text { late } 4^{\text {th }} \text { /early } 3 \text { rd millennium } \\
\text { BCE }\end{array}$ & $\begin{array}{c}\text { charred } \\
\text { encrustations }\end{array}$ & & $\begin{array}{c}\text { use wear } \\
\text { analysis + FTIR }\end{array}$ \\
\hline 503 & $\mathrm{TP}$ & $\begin{array}{c}\text { late } 4^{\text {th }} / \text { early } 3 \text { rd millennium } \\
\text { BCE }\end{array}$ & $\begin{array}{c}\text { charred } \\
\text { encrustations }\end{array}$ & & $\begin{array}{c}\text { use wear } \\
\text { analysis + FTIR }\end{array}$ \\
\hline 504 & $\mathrm{TP}$ & $\begin{array}{l}\text { late } 4^{\text {th }} / \text { early } 3 \text { rd millennium } \\
\text { BCE }\end{array}$ & $\begin{array}{c}\text { charred } \\
\text { encrustations }\end{array}$ & & $\begin{array}{c}\text { use wear } \\
\text { analysis + FTIR }\end{array}$ \\
\hline 2 & $\begin{array}{l}\text { OC- } \\
\text { VC }\end{array}$ & $\begin{array}{l}\text { middle/late 3rd millennium } \\
\text { BCE }\end{array}$ & $\begin{array}{l}\text { use wear }+ \text { charred } \\
\text { encrustations }\end{array}$ & use wear + soot & $\begin{array}{c}\text { use wear } \\
\text { analysis + FTIR }\end{array}$ \\
\hline 138 & $\begin{array}{l}\text { OC- } \\
\text { VC }\end{array}$ & $\begin{array}{l}\text { middle/late 3rd millennium } \\
\text { BCE }\end{array}$ & $\begin{array}{c}\text { charred } \\
\text { encrustations }\end{array}$ & use wear + soot & $\begin{array}{c}\text { use wear } \\
\text { analysis + FTIR }\end{array}$ \\
\hline 11 & $\begin{array}{l}\text { OC- } \\
\text { VC }\end{array}$ & $\begin{array}{l}\text { middle/late 3rd millennium } \\
\text { BCE }\end{array}$ & $\begin{array}{c}\text { charred } \\
\text { encrustations }\end{array}$ & use wear & $\begin{array}{c}\text { use wear } \\
\text { analysis + FTIR }\end{array}$ \\
\hline
\end{tabular}

Table 2 - Sampling of archaeological materials investigated, use traces identified, and scientific analyses applię.

5 Methodology applied in this research combine use wear analysis, spectroscopic analysis and 6 experimental archaeology.

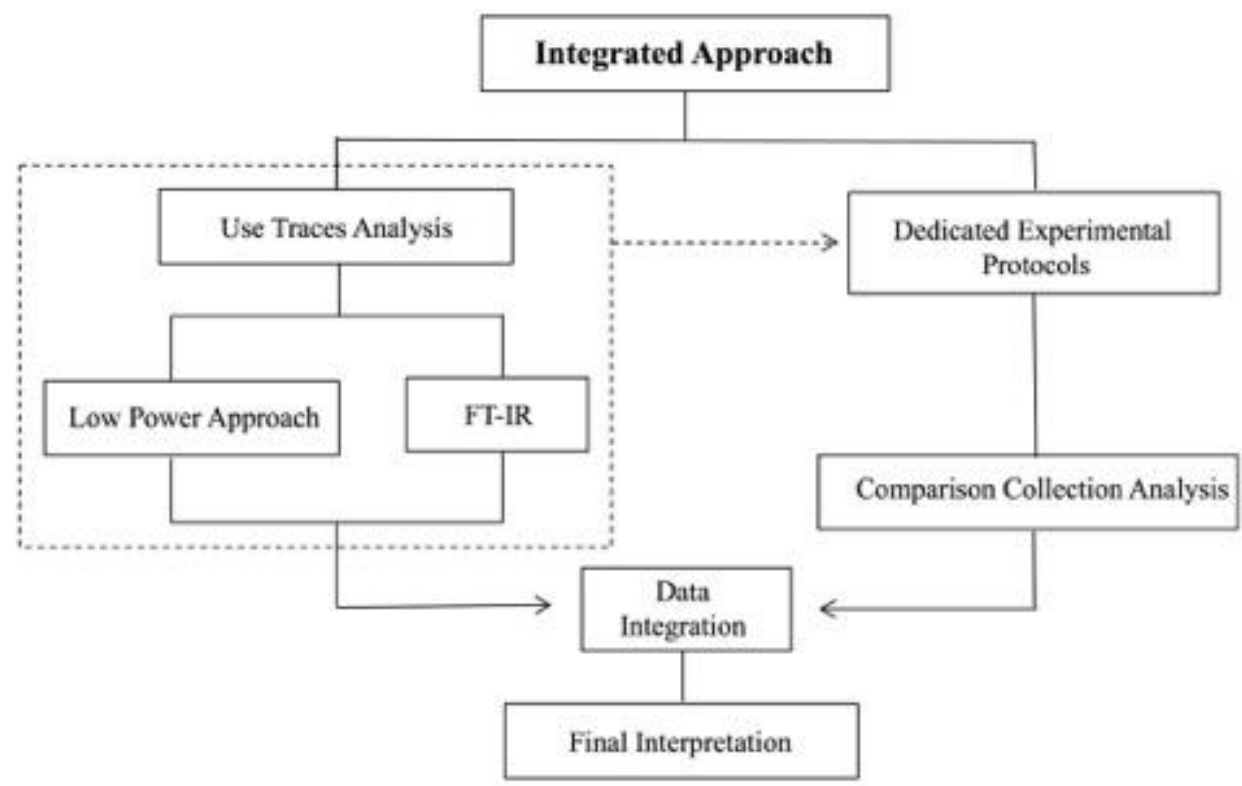

Figure 3 - Methodology applied to the study of ceramic vessels? 
3.2.1 Use wear analysis

2 Use wear analysis focused on the alterations to pottery surfaces that were generated during the 3 vessel's use.

4 For the purposes of this work, both archaeological and experimental traces were observed and 5 defined using a low power approach combining naked eye observations and a Nikon SMZ-U 6 stereo microscope, with $1 \mathrm{X}$ objective, $10 \mathrm{X}$ eyepiece and magnifications from $0.75 \mathrm{X}$ to $7.5 \mathrm{X}$ 7 (Tringham et al., 1974; Van Gijn, 2010; Vieugué, 2015). The study covered both internal and 8 external ceramic surfaces and pursued a detailed investigation by dividing the vessel into four 9 compositional zones: base, wall, rim and handles (Forte, 2015).

10 Within the approach proposed by this paper, ceramic use wear has been categorised according 11 to surface topography, and texture, shape, frequency, incidence, orientation and edge of traces, 12 in order to objectively record them and investigate the associated wear mechanisms (Tab. 3; 13 Fig. 4).

\begin{tabular}{ll}
\hline \multicolumn{1}{c}{ Variables } & \multicolumn{1}{c}{ Wear Variables } \\
\hline $\begin{array}{l}\text { Surface } \\
\text { Topography }\end{array}$ & $\begin{array}{l}\text { Flat, sinuous, uneven } \\
\text { fatigue wear/abrasive wear/ thermal alterations/chemical } \\
\text { alterations/tribochemical wear } \\
\text { Striations/ scratches/ grooves/ depressions/ levelling/ rounding/ } \\
\text { fractures/ cracks/ spall detachment/ pits/ soot/ food residues/ } \\
\text { discolorations. } \\
\text { internal / external surface; base / wall (lower - mid - upper) / rim / } \\
\text { handles } \\
\text { Traces }\end{array}$ \\
$\begin{array}{l}\text { Lounded / oval / linear } \\
\text { Shape }\end{array}$ & $\begin{array}{l}\text { smooth / striated / coarse } \\
\text { Texture }\end{array}$ \\
Frequency & isolated / closed / connected \\
Incidence & shallow / deep /mixed \\
Cross section & u-shaped / v-shaped / mixed \\
Orientation & vertical / horizontal / oblique / circular /mixed \\
morphology & regular / irregular / rounded / sharp \\
\hline
\end{tabular}

Table 3 - Relationships between tribological, thermal and chemical mechanisms and traces observed on archaeological materials, derived from the hypothesis of Adams et al. (2009) and Vieugué (2014, pp.225).

15

16

Topography variable lead to define the original surface features affected by the wear mechanisms to understand their development (Adams et al., 2009). On pottery vessels, it refers to the physical characteristics of surface treatments usually applied during the last technological process of vessel's modelling and it can be applicable to each vessel's zone analysed (Fig. 4).

Traces left by wear processes were distinguished from each other on the basis of their features, namely: texture, shape, frequency, incidence, orientation and edge. 


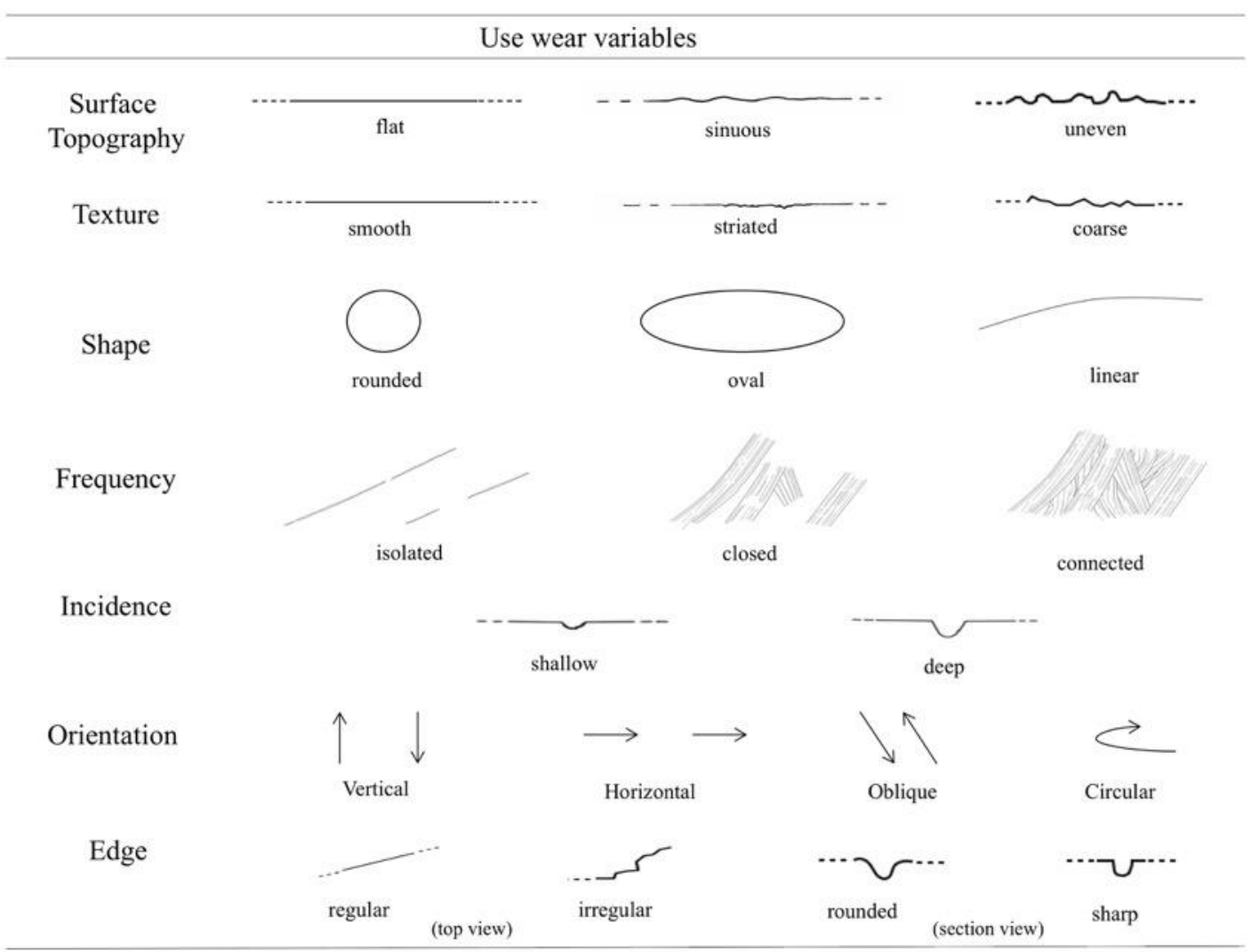

Figure 4-Graphic representation of criteria applied during the use traces analysis of archaeological and experimental ceramic vessels.

2 Texture refers to wear surface variables, being either smooth, striated or coarse. The shape of 3 the trace evidence can be rounded, oval or linear; its frequence within each of the vessel's zones 4 is defined as either isolated, closed or connected. Incidence concerns the depth relative to the 5 original surface and is recorded depending on the wear amplitude (e.g. a depression is wider 6 than it is deep, while a pit is deeper than it is wide). Orientation refers to the direction of a 7 trace's development according to the vessel's vertical axis; it can be vertical, horizontal, 8 oblique and circular. The edge variable describes the morphology of the boundaries of the wear 9 as being regular or irregular if observed from above, and rounded or sharp if observed in cross10 section.

11 Integrating each of these variables allows for a definition of the physical aspects of wear and 12 an understanding of whether their morphology is due to a detachment by mechanical, thermal 13 or chemical processes, or by a combination thereof.

\subsubsection{Spectroscopic Analysis}

16 The recurrence of consistent and localised amorphous dark residues, observed along the 17 internal and external surfaces of the vessels discussed here, led to the selection of an integrated 18 analysis of wear distribution, combining ethnoarchaeological and experimental comparison with a compositional definition of internal encrustations, achieved through a non-invasive spectroscopic analysis (Lemorini et al., 2014; Lettieri, 2015; Nunziante Cesaro and Lemorini, 2011; Shillito et al., 2009).

The dark residues identified on pottery during the macroscopic observation were selected for an infrared analysis (FTIR), with the aim of obtaining a preliminary understanding of the charred encrustations that might support the hypotheses regarding the use activities involving these vessels. 
1 Microsamples extracted from areas without extraneous substances and areas with charred 2 residues were mixed with $\mathrm{KBr}$ excess. The FTIR analysis was performed using an Alpha 3 (Bruker) spectrometer, equipped with the Diffuse Reflectance Infrared Fourier Transform 4 (DRIFT) module. The spectra were obtained in the $4000-375 \mathrm{~cm}^{-1}$ range with a spectral 5 resolution of $4 \mathrm{~cm}^{-1}$, collecting 200 scans or more.

6

\subsubsection{Experimental archaeology}

8 The application of experimental protocols in the study of use traces on pottery vessels enabled 9 a detailed investigation of the processes underlying the modifications of the ceramic material, 10 allowing for the distinction between traces caused by use and those attributable to post11 depositional events (Skibo, 1992).

12 In the study here presented, the application of experimental archaeology has been structured 13 with the intention of producing a dedicated experimental framework, enabling a precise comparison between the archaeological traces identified on the flat base of the subject vessels and use wear generated by specific food manipulation processes. The experiments performed are based upon empirical principles proposed by studies of the 1980s and 1990s and aim to: 1) produce updated photographic documentation of the more frequent use traces generated by cooking activities, and 2) test if a dedicated tribological analysis can lead to a more detailed description of the mechanisms causing such traces, and recognise the possible overlapping of different wear processes.

\begin{tabular}{|c|c|c|c|c|c|}
\hline ID & Position & Cooking technique & $\begin{array}{c}\text { Food } \\
\text { Temperature } \\
\end{array}$ & Time & $\begin{array}{l}\text { The experimental pottery } \\
\text { vessels presented in this }\end{array}$ \\
\hline \multirow[t]{2}{*}{$1 \mathrm{a}$} & \multirow[t]{2}{*}{ lateral to the fireplace } & \multirow[t]{2}{*}{ Dry (toasted cereals) } & \multirow[t]{2}{*}{200} & $\begin{array}{l}23 \\
224\end{array}$ & $\begin{array}{l}\text { work were built according } \\
\text { to technological (Forte, }\end{array}$ \\
\hline & & & & 25 & 2015; Forte and \\
\hline \multirow[t]{2}{*}{$1 b$} & \multirow[t]{2}{*}{ lateral to the fireplace } & \multirow[t]{2}{*}{ Dry (toasted cereals) } & \multirow[t]{2}{*}{200} & 226 & Medeghini, 2017) and \\
\hline & & & & 27 & morphological features \\
\hline \multirow[t]{2}{*}{$2 \mathrm{a}$} & \multirow[t]{2}{*}{ lateral to the fireplace } & \multirow[t]{2}{*}{ Wet (cereals soup) } & \multirow[t]{2}{*}{100} & 48 & (Anzidei and Carboni, \\
\hline & & & & 29 & 2011; Anzidei et al., 2007, \\
\hline \multirow[t]{2}{*}{$2 b$} & \multirow[t]{2}{*}{ lateral to the fireplace } & \multirow[t]{2}{*}{ Wet (cereals soup) } & \multirow[t]{2}{*}{200} & 30 & 2011) of the \\
\hline & & & & 31 & archaeological ceramic \\
\hline \multirow[t]{2}{*}{$2 \mathrm{c}$} & \multirow[t]{2}{*}{ lateral to the fireplace } & \multirow[t]{2}{*}{ Wet (cereals soup) } & \multirow[t]{2}{*}{500} & 32 & materials from the current \\
\hline & & & & 33 & Rome area. \\
\hline \multirow[t]{2}{*}{$3 a$} & \multirow[t]{2}{*}{ lateral to the fireplace } & \multirow[t]{2}{*}{ Wet (meat stew) } & \multirow[t]{2}{*}{200} & 334 & A coiling technique was \\
\hline & & & & 35 & applied for the modelling \\
\hline \multirow[t]{2}{*}{$3 b$} & \multirow[t]{2}{*}{ lateral to the fireplace } & \multirow[t]{2}{*}{ Wet (meat stew) } & \multirow[t]{2}{*}{200} & 336 & of 4 open vessels with a \\
\hline & & & & 37 & flat base, utilising \\
\hline \multirow[t]{2}{*}{$3 c$} & \multirow[t]{2}{*}{ lateral to the fireplace } & \multirow[t]{2}{*}{ Wet (meat stew) } & \multirow[t]{2}{*}{200} & 338 & semifine and coarse clay \\
\hline & & & & 39 & pastes collected from the \\
\hline \multirow[t]{2}{*}{ 4a } & \multirow[t]{2}{*}{ lateral to the fireplace } & \multirow[t]{2}{*}{ Wet (legume soup) } & 200 & 340 & Rome area and compatible \\
\hline & & & & 41 & with the raw materials \\
\hline $4 \mathrm{~b}$ & lateral to the fireplace & Wet (legume soup) & 200 & 342 & used in the archaeological \\
\hline & & & & 43 & pottery production (Forte \\
\hline $4 c$ & lateral to the fireplace & Wet (legume soup) & 300 & 344 & and Medeghini 2017). \\
\hline
\end{tabular}
$800-900{ }^{\circ} \mathrm{C}$. The internal and external surfaces of the vessels were treated with a smoothing technique and a polishing technique, according to the features observed on the surfaces of archaeological specimens (Forte, 2015) (Fig. 5). 
In light of the palaeobotanical and archaeozoological remains documented in the archaeological contexts of the Rome area (see 3.1), cereals, legumes and meat were chosen and processed, following basic techniques such as dry (toasting of cereals) and wet (soups and stews of cereals, legumes and meat) cooking. Considering the flat base of the vessels and the absence of sooting traces on the external base, exception made for one sample (ID138), a lateral position of the vessels to the fireplace has been hypothesised; For this reason the experimental vessels were placed laterally to the fireplace up to $10-15 \mathrm{~cm}$ of distance (Tab. 4).

8 Eleven food processing experiments were performed at high temperatures (three experiments

9 for each vessel, exception made for toasting repeated twice, see Table 4), during which the 10 internal and external carbonisation processes were monitored.

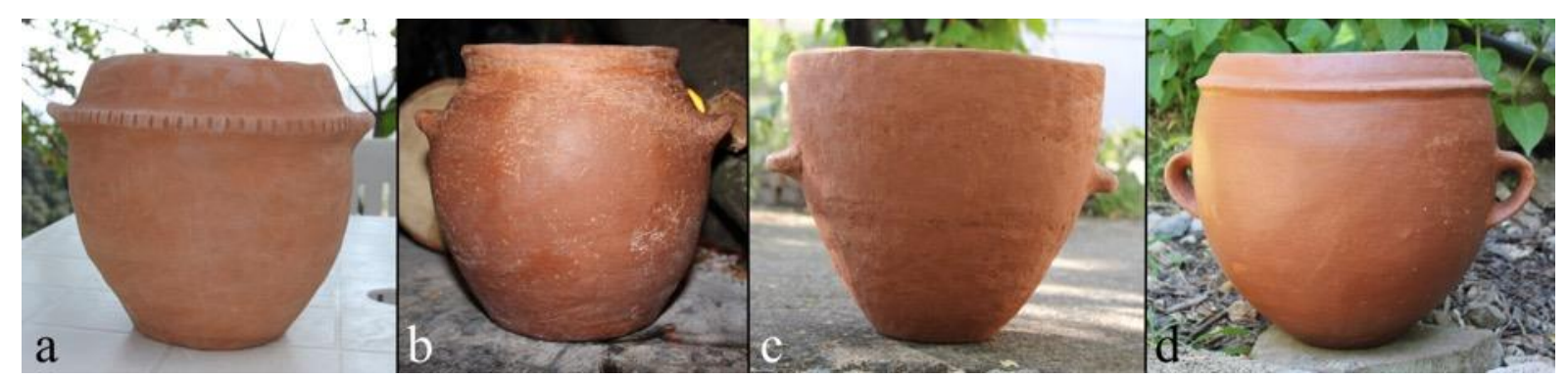

Figure 5 - Experimenetal pottery vessels before the use as cooking pots: a: ID 1; b: ID 2, c: ID 3; d: ID 13 .

The experiments included the intentional reproduction of food carbonisation in order to understand why the archaeological vessels feature wide carbonised areas in their internal surfaces, which usually should be free from carbonisation processes (as documented in ethnoarchaeological studies, see Skibo, 1992), and to determine whether these traces are associable to specific recurrent use processes or casual events. To this end, surface alteration was monitored both during direct contact with the flame and during prolonged exposure to indirect heat.

\begin{tabular}{|c|c|c|c|c|c|c|c|c|}
\hline \multicolumn{9}{|c|}{ Experimental use wear } \\
\hline \multirow{2}{*}{$\begin{array}{l}\text { Exp. } \\
\text { ID }\end{array}$} & \multicolumn{2}{|c|}{ Abrasive wear } & \multicolumn{2}{|c|}{ Fatigue wear } & \multicolumn{2}{|c|}{ Thermal stress } & \multicolumn{2}{|c|}{ Corrosive wear } \\
\hline & internal & external & internal & external & internal & external & internal & external \\
\hline 1 & & & & & $\begin{array}{c}\text { charred } \\
\text { encrustation }\end{array}$ & $\begin{array}{l}\text { discoloration/ } \\
\text { soot }\end{array}$ & & \\
\hline 2 & & & & & $\begin{array}{c}\text { cracks / charred } \\
\text { encrustations }\end{array}$ & soot & & \\
\hline 3 & & $\begin{array}{c}\text { depressions/ } \\
\text { striations/ } \\
\text { scratches/ } \\
\text { grooves }\end{array}$ & & & $\begin{array}{c}\text { spall } \\
\text { detachments/ } \\
\text { cracks/ charred } \\
\text { encrustations }\end{array}$ & $\begin{array}{c}\text { spall } \\
\text { detachments/ } \\
\text { cracks/soot }\end{array}$ & & \\
\hline 4 & & $\begin{array}{c}\text { depressions/ } \\
\text { striations/ } \\
\text { scratches/ } \\
\text { grooves }\end{array}$ & & $\begin{array}{c}\text { spall } \\
\text { detachment }\end{array}$ & $\begin{array}{l}\text { cracks/ charred } \\
\text { encrustations/fat } \\
\text { residues }\end{array}$ & soot & depressions & \\
\hline
\end{tabular}

Table 5 - Use alterations identified on experimental pottery vessels. 


\subsection{Experimental use wear and residues}

This experiment enabled the creation of a dataset regarding the most recurrent traces deriving from controlled use activities (Tab. 5), augmenting current available knowledge about wear processes affecting specific ceramic vessels.

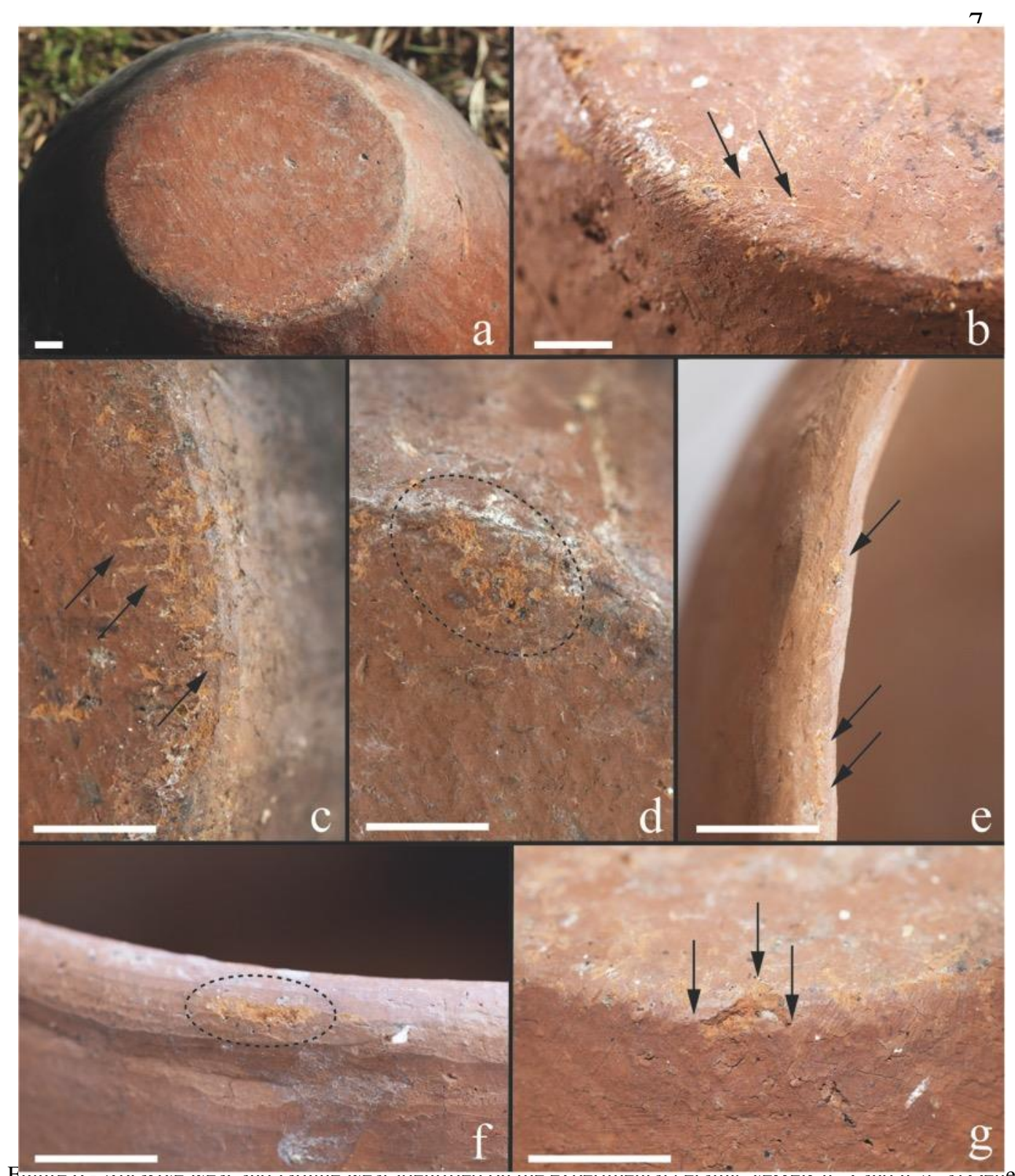

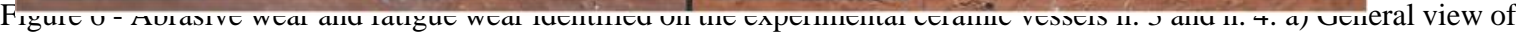
the external base of the vessel featuring abrasive processes (Exp. ID 4); b) Striations and scratches (Exp. ID 3) on a flat topography; c) Grooves on a sinuous topography (Exp. ID 4); d) Depressions on a sinuous topography (Exp. ID 4); e) Depression along limited portions of the vessel rim on a sinuous topography (Exp. ID 4); f) Depression lateral to the vessel rim on an uneven topography (Exp. ID 4); g) Spall detachment caused by mechanical stress on an uneven topography (Exp. ID 3) (white bar equals to $1 \mathrm{~cm}$ ).

\subsubsection{Abrasive wear}

In two experiments (ID 3 and 4) the involved tribological mechanisms developed different kinds of traces. In accordance with the tribological variables recorded during the first studies on ceramic abrasion (Schiffer and Skibo, 1989, Skibo and Schiffer, 1987; Skibo et al., 1997), 
it was possible to document the different kinds of wear derived from abrasive processes, both with and without an intermediate liquid substance working as lubricant.

Vessels used on hard surfaces (e.g. stone floor) during the first experiments were affected by

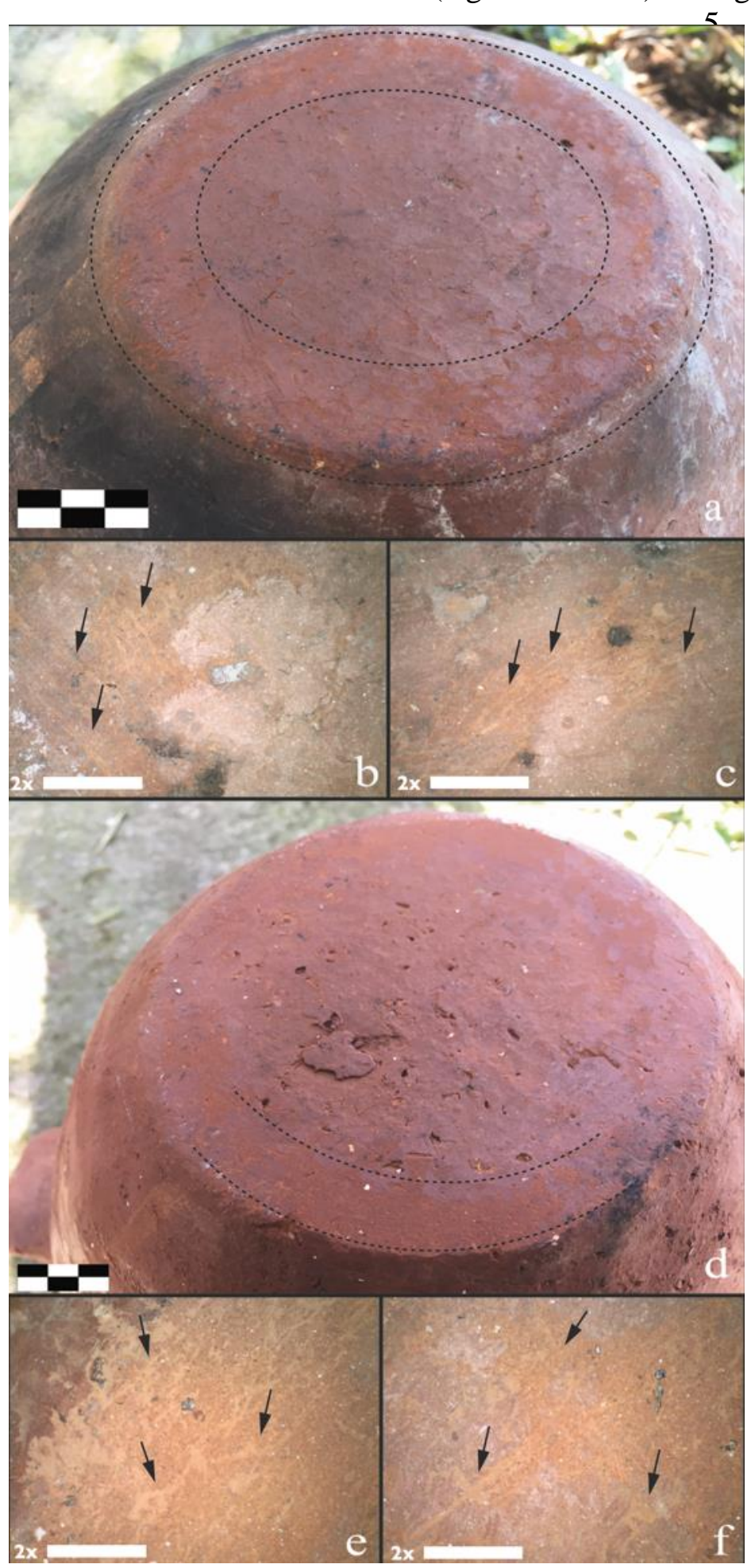
abrasive wear in the form of depressions, striations, scratches and grooves (Fig. 6a). These traces are mostly located on the external vessel surfaces and are characterised by recurrent distribution patterns.

Abrasive wear typically developed along the peripheral area of the external base. Striations, scratches (Fig. 6b) and grooves (Fig. 6c) recur with a linear shape, coarse texture, closed frequency, mixed incidence, mixed cross section, and irregularsharp edge morphology. Irregular depressions, intended as a subsidence of the original sinuous and uneven surface with an amplitude greater than its depth, are particularly common. These are characterised by a coarse texture, closed distribution, shallow incidence, U-shaped cross section, and irregular-sharp edge morphology (Fig. 6d-e).

These alterations were produced by the continued displacement - usually by dragging - of the vessels before, during and after the experimental cooking process.

These wear mechanisms started to affect the most protruding parts usually surfacing sinuous and uneven topographies.

During first experiments, the vessel was moved across hard or mediumhard surfaces (e.g. stone or ceramic support). without any intermediate water working as lubricant.

Furthermore, abrasive wear, particularly in the form of depressions, developed also over limited portions of the rims of vessels

Figure 7 - Abrasive wear identified on the experimental ceranti6 vessels: a and d correspond respectively to general view of ID 4 an $\$ 7$ after use on a smoothed medium/soft hard surface (e.g. ceramic plaind, opaque areas results by wear processes; polished areas corresponds lo resisual zones of original surface treatment; b, c, e, f: striations featufifg ID 4 and 3; (white bar equals to $1 \mathrm{~cm}$ ). n. 3 and 4. These traces developed suring non-use periods, when the vessels were moved and stored upside down on a hard floor (Fig. 6e). 
In one case, the location of the abrasive wear is lateral to the rim (Fig. 6f) due to the contact between two adjacent vessels stored upside down on the floor.

Abrasive wear developed after repeated uses on ID 3 and 4 in the form of levelling of too-wide or too-narrow surface portions, alternate to isolated striations, and largely affected areas that protruded from the topography (Fig. 7 a-f).

These traces were produced by a tribological system comprising two surfaces with similar physical and compositional characteristics (medium/soft hard surfaces), as a ceramic plain, with the presence of water as lubricant. The presence of water between the two surfaces was due to it's leaking during the first steps of food preparation or after the vessel cleaning; in both cases a small amount of water deposited along the external base favoring tribological processes during the vessel displacements. Activities involving water took usually 10 minutes for each vessel during the repeated experiments and vessels displacements were made frequently to observe traces associated to these gestures.

The two vessels used at the same way and for the same period of time developed traces differently depending on the topography of the base's surface. The vessel 3 (Fig. 7d) shows an invasive abrasive wear than vessel 4 (Fig. 7a). In the first case the flat topography has been involved homogeneously in the abrasive process and was modified without leaving residual zones of the original surface exception made for the central area of the vessel. In the second case, in the same amount of time, the alteration affected the protruding parts of the uneven and sinuous surface. According to the Theory of Ceramic Abrasion defined by Schiffer and Skibo (1989), the sliding movement, aided by water leaked and deposited on the base led to the dissolution of the external particles, which levelled progressively during the sliding movement. Abrasive processes and related fatigue forces started to affect the surface areas where physical pressure was concentrated (Fig. 7); for example, in the case of a vessel base rotation, holding the vessel with two hands, the forces were distributed homogeneously and the wear process affected all protruding parts in the same way (Fig. 7 a, d). During a sliding movement, however, wear started to develop over the area closer to the direction of movement (Fig. 7 d). These processes caused a softening of the previous invasive use wear and an obliteration of the superficial traces (compare Fig. 6a-d with Fig. 7a-f).

\subsubsection{Fatigue wear}

In one experimental vessel (Exp. ID 3) a spall detachment occurred along the external base due to an impact with a hard surface. The alteration affected the articulation base/wall and was caused by a mechanical stress from the bottom up. This generated a spall detachment with an oval shape, coarse texture, isolated frequency, deep incidence, mixed cross section, horizontal orientation and irregular/sharp edge morphology (Fig. 6g).

\subsubsection{Thermal alterations}

Thermal stresses such as prolonged exposure to the fire, sudden temperature variations or shocks can cause wear in the form of spall detachments, cracks and fractures (Hally, 1983; Skibo, 1992, 2015) (See Fig. 8-11).

Spall detachments caused by thermal stress were reproducible on the experimental vessels' internal and external surfaces (Exp. ID 4). These are characterised by a rounded shape, coarse texture, isolated frequency, deep incidence, U-shaped cross section and irregular-sharp edge morphology. These types of alterations consist of small superficial cracks in which soot or food residues can be absorbed (Fig. 8a-d). Experiments confirmed that mechanical processes (e.g. tools used in contact with the internal surfaces to mix the vessel's content or by unintentional hits against the external surface) affecting superficial cracks can stress the surface and lead to particle detachment. In one case of thermal stress (Exp. ID 2) a long crack developed, extending from the rim to the lower part of the wall, damaging the pot without breaking it (Fig. 8e). 
1 During the cooking activity, organic and inorganic substances adhered to the ceramic surface 2 through molecular interactions, leading to the formation of internal and external carbon 3 deposits and localised alterations of the surface colour (Hally, 1983; Skibo, 1992, 2015).

4 During cooking activities the prolonged exposure of a vessel to high temperatures (over 100 $5{ }^{\circ} \mathrm{C}$ ) can produce a carbonisation of the content due to the total evaporation of the cooking water

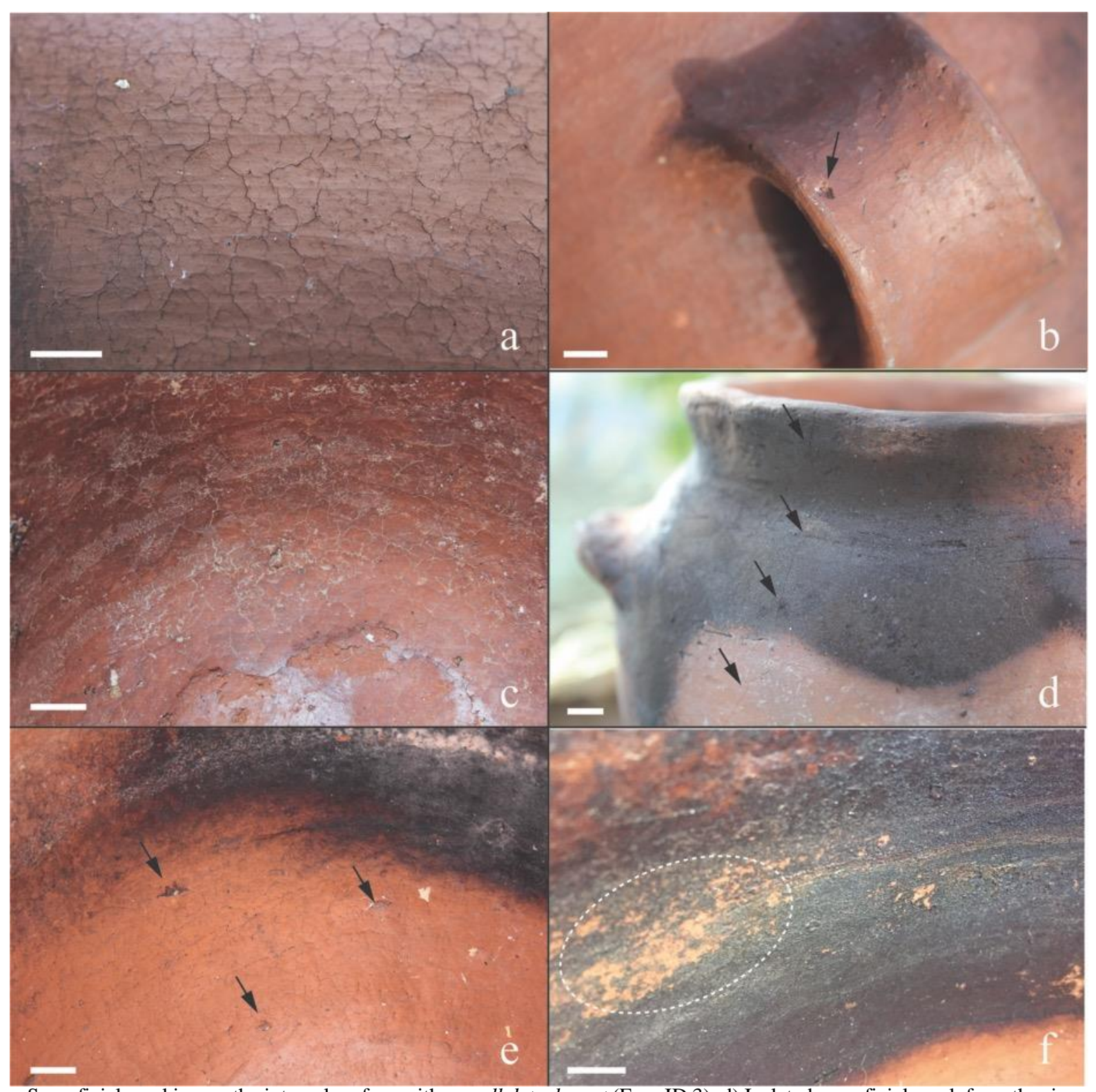

Superficial cracking on the internal surface with a spall detachment (Exp. ID 3); d) Isolated superficial crack from the rim to the lower part of the vessel (Exp. ID 2); e) Diffused cracking on internal surface wall with isolated spall detachments (Exp. ID 4); f) superficial depressions developed on the surface of the internal wall (Exp. ID 4) (white bar equals to $1 \mathrm{~cm}$ ).

6 and of the moisture present in both the food and the ceramic pores; this results in an area of 7 high temperature (Kobajashi, 1994; Skibo, 1992, 2013). This procedure consists in the 8 transformation of organic materials into carbon deposits and features specific patterns of 9 consistency and distribution corresponding to different cooking techniques (Hally, 1983). 
1 During dry cooking, namely the toasting of cereals, a temperature of $200{ }^{\circ} \mathrm{C}$ was reached (Exp. 2 ID 1) and caused the carbonisation of the food inside (Fig. 9b). The charring process began at 3 the point of maximum temperature of the whole vessel, as also attested in ethnoarchaeological 4 studies (Kobajashi, 1994; Skibo, 1992, 2013).

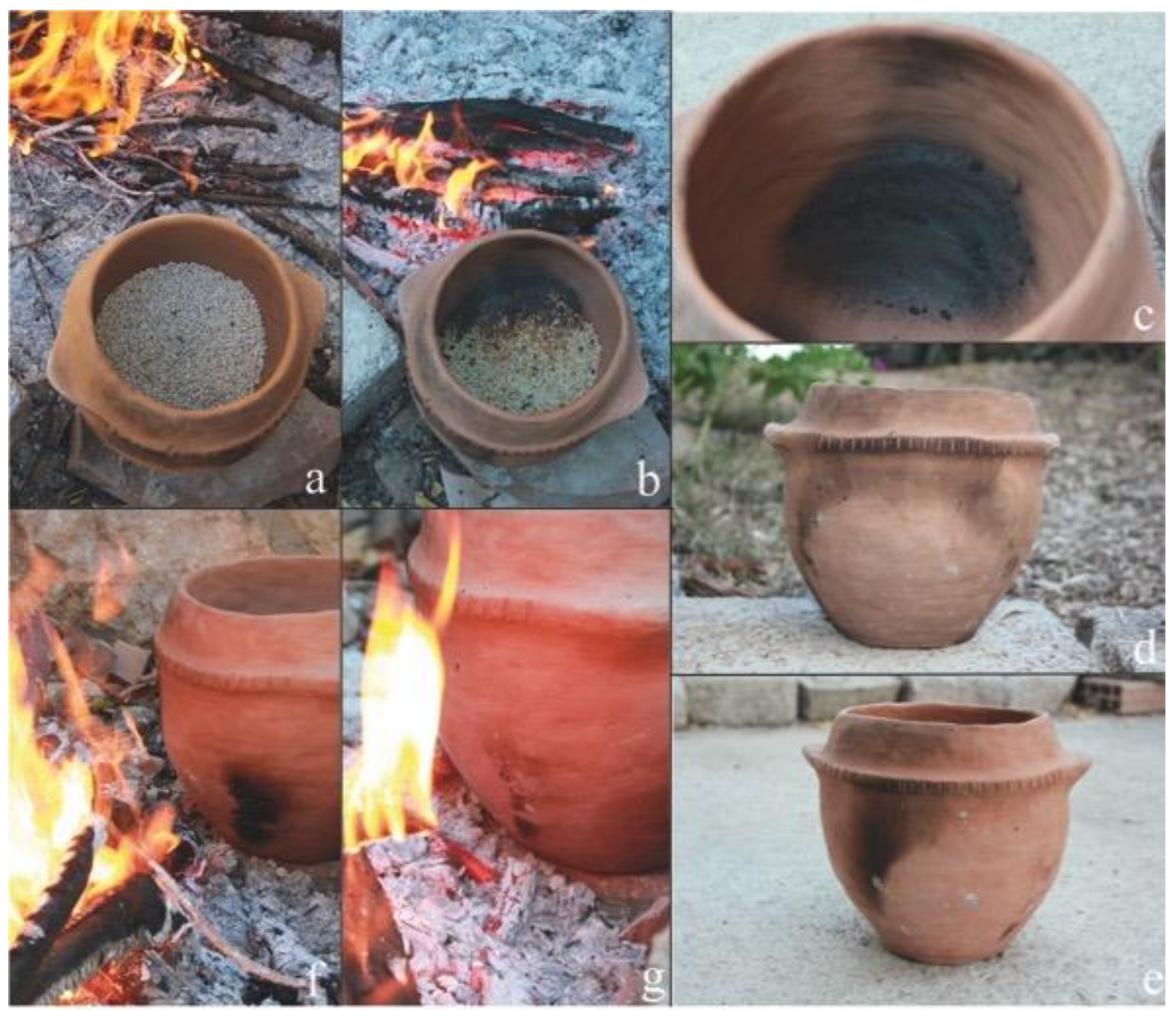

Figure 9 - Experimental toasting of cereals (Exp. ID 1): a) Location of the vessel near to the fireplace; b) Initial cereal charring along the lower part of the internal wall; c) Charring traces on the internal surface of the vessel; d/e) Disappearance of the external sooting alterations during the latest experimental framework.

During the experiment the vessel was placed laterally to the fireplace (Fig. 9a); at $150-200{ }^{\circ} \mathrm{C}$ the dry contents began to char along the internal surface in the lower part of the wall, corresponding to the point of highest temperature due to the proximity of the heat source (Fig. 9b).

10 Carbonisation of waterless content produced an oval, labile and powdery dark deposit along 11 the internal wall surface, generated by the dehydration and pulverisation of the cereals' organic component, resulting in small and closed charred encrustations (Fig. 9c). Wear location corresponded to the mid-lower part of the wall, in particular along the wall/base articulation, namely the area covered by the food during cooking (Fig. 9a-b). Moreover, the evaporation of food particles during the dehydration process caused a slightly closed vertical band of carbon deposit along the upper wall (Fig. 9c). This latter type of alterations refers to external deposits, known as soot, which developed along the side of the vessels exposed to the fireplace and are due to the incomplete carbonisation of wood fuel (Skibo, 1992, 2013) (Fig. 9d-e). 
2 The mid-lower part of the wall features an oval area of oxidation, whereas the internal carbon 3 deposits were concentrated on the mid-upper part of the wall, extending until the rim (Fig. 9b, d). This oxidised area was caused by the high temperatures reached by direct contact with the flame, which resulted in the complete disappearance of the deposits. On the other hand, soot deposit is present on the upper part of the wall. (Fig. 9f-g).

The external surface of the vessel base, which is in contact with the floor during cooking, 8 remained free from such alterations, and the internal surface in contact with the content 9 remained non carbonised as well.

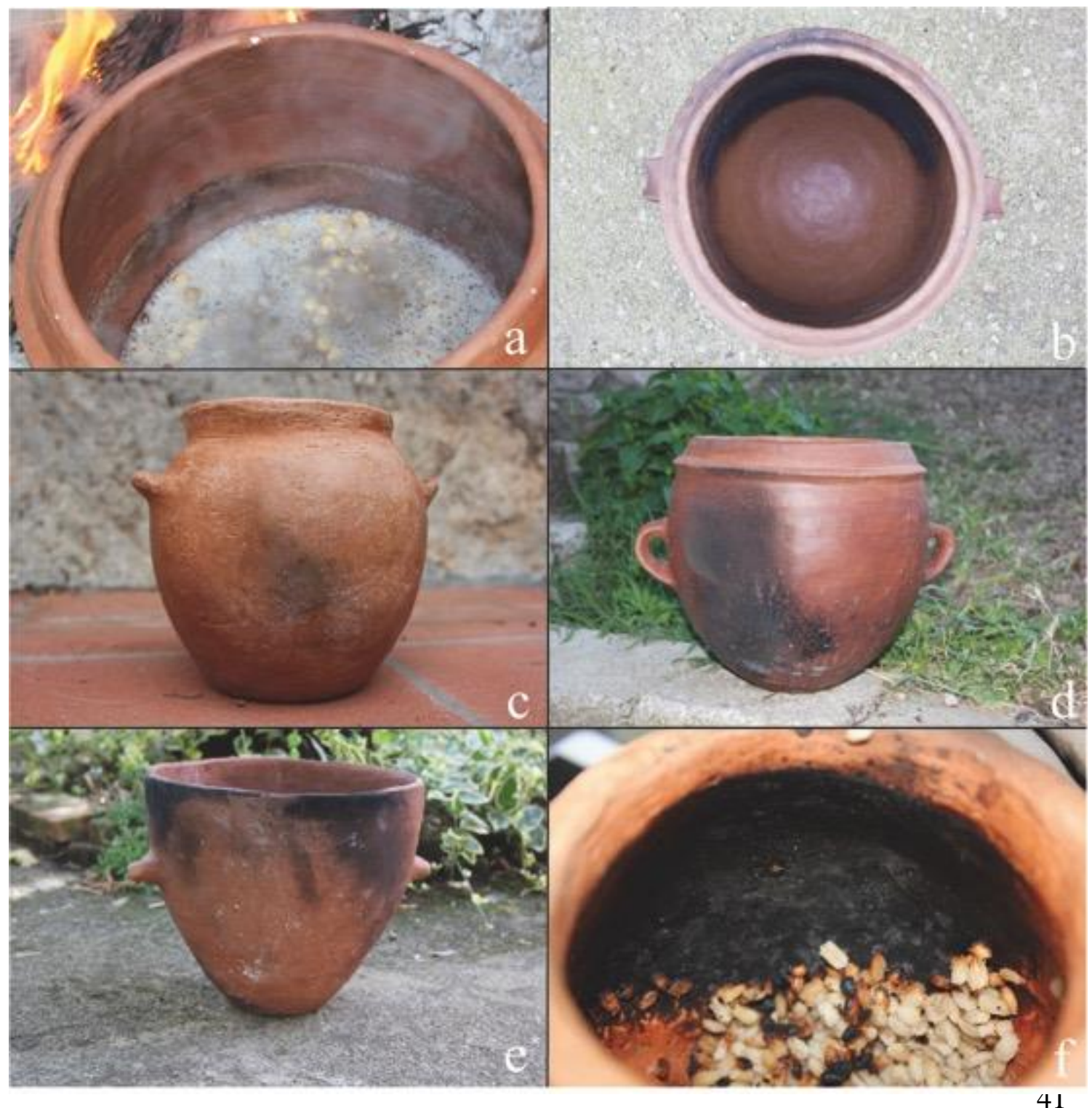

Figure 10 - Thermal alterations identified on experimental ceramic vessels: a) Deposition process of the food particles along the hottest spot of the internal wall during the experimental cooking (Exp. ID 4); b) Circular half-band of carbon deposit due to the carbonisation of food particles after the experimental cooking (Exp. ID 4); c) Sooting concentrated along the external middle wall surface deposited during the first experimental cooking of Exp. ID 2, positioned far away from and laterally to the fireplace; d) Sooting concentrated over the entire external wall deposited during the second experimental cooking of Exp. ID 4, positioned near and laterally to the fireplace; e) Sooting concentrated along the upper part of the external wall deposited during the third experimental cooking of Exp. ID 3, positioned near and laterally to the fireplace; f) Charring of cereals during the third experimental cooking of Exp. ID 2. 
In the case of the vessels used for wet cooking, which contained a soup of cereals (whole cereals or cereal flour), legumes or meat stew (Exp. ID 2, 3 and 4), the vessels reached temperatures of $300-400{ }^{\circ} \mathrm{C}$ followed by a carbonisation of their contents (Tab. 4).

The use of different vessels facilitated a better understanding of the traces related to food charring which develop on the internal and external surfaces of a vessel. It was thus possible to analyse the various relationships between specific patterns of carbon deposits and the specific processing of a given kind of food, according to general principles also documented in ethnoarchaeological works (Arthur, 2002, 2003; Skibo, 1992; Valamoti, 2010).

During the first and second cooking attempts all vessels, which were located laterally to the fireplace, were used to cook soups or stews at different temperatures (Tab. 4). All the vessels featured a particular recurrent pattern: a dark half-circular band along the hottest spot of the internal wall (Fig. 10a), similar to but wider than the circular ring identified by Skibo (1992) on the kalinga cooking pots. This kind of alteration was produced by the concentration of carbon deposits along the band immediately above the water level.

Deposition of organic content in this area of significant heat led to the carbonisation of particles in a more or less evident carbon deposit; the internal wall surface, however, which is in contact with water and experiences a lower temperature, remained clean (Fig. 10b). From this experiment it also emerged that the location of such traces coincides with the level of the water present in the vessel during cooking.

A specific pattern of carbon deposits was observed in all the vessels at their last experimental use. The trace occurred in vessels with a slightly closed shape and was produced by food particles that, during evaporation, adhered to the internal surface of the upper wall and rim (Fig. 9c).

During the final experimental cookings, in two vessels (n. 2 and 4) the exposure to the high temperature permitted the monitoring of how new use traces can modify and even delete previously developed ones.

Exposure to temperatures higher than $300{ }^{\circ} \mathrm{C}$ led to the evaporation of water and food moisture and the consequent carbonisation of the organic contents. Depending on the cooking duration,

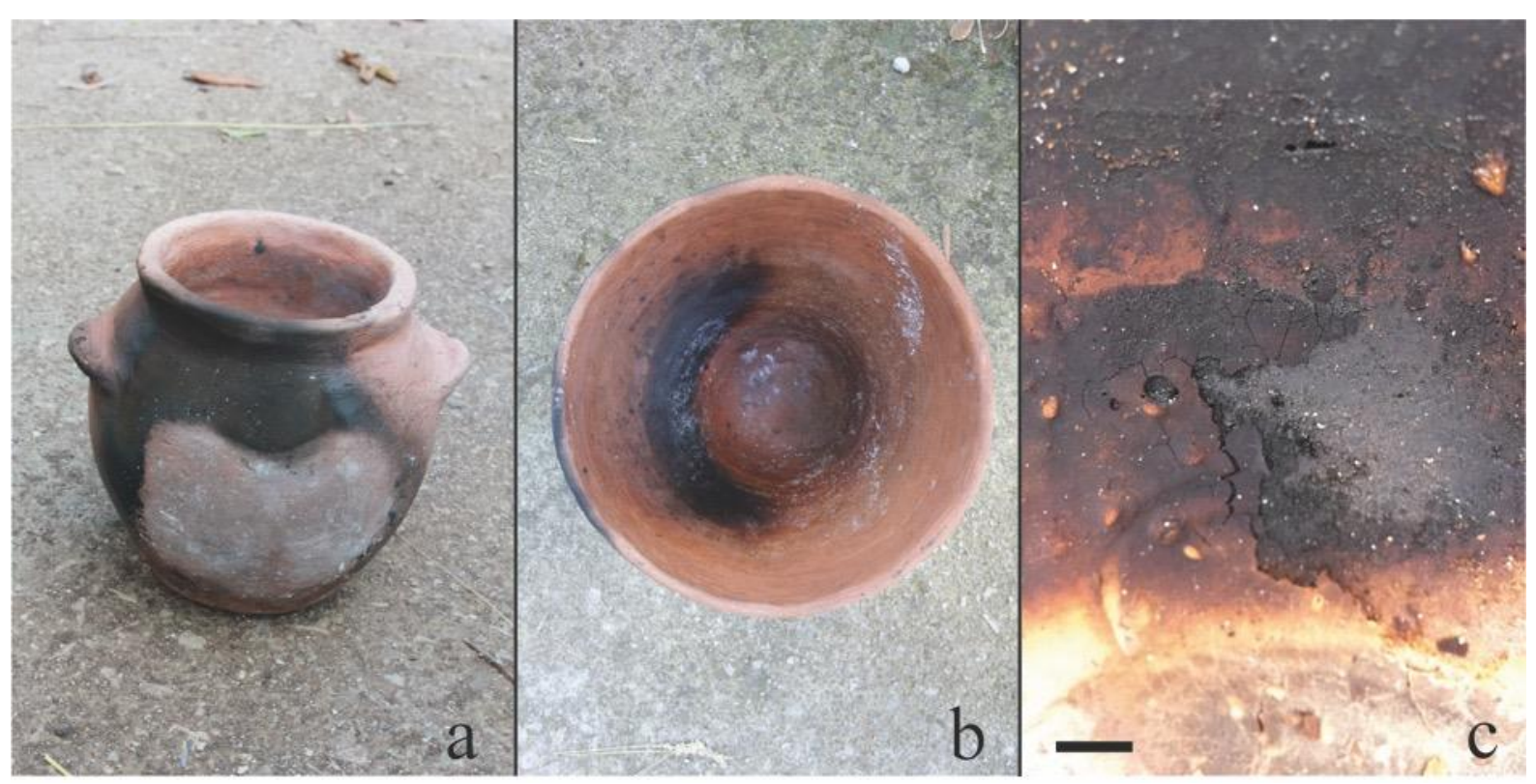

Figure 11 - Thermal alterations identified on experimental ceramic vessels: a) Discolouration of the external wall surface resulting from exposure to high temperatures (Exp. ID 2); b) Internal black half-band, due to a charring process of the contents, extended from the level reached by the food to the lower part of the wall (Exp. ID 3); c) Charred encrustation developed between the ceramic wall and a layer of cereal flour soup not yet completely charred (Exp. ID 4) (black bar equals to $1 \mathrm{~cm}$ ). 
the experiment led to the development of extended and consistent charred encrustations. Experiment ID 2 features an intense charred encrustation, extending from the middle to the upper part of the wall until the rim (Fig. 10f).

A light grey circular area on external surfaces, which obliterated the previous soot deposits (Fig. 11a), is the result of long exposure to high temperatures, probably above $800{ }^{\circ} \mathrm{C}$. Exposure to such a high temperature affected the mineralogical structure of the ceramic and led to a visible localised discolouration (Hally, 1983).

Moreover, the strong thermal stress damaged the vessel itself, producing cracks running from the rim to the middle section of the wall. However, these cracks did not cause the pot to break (Fig. 11a).

Experiment ID 3 featured the formation of a dark band affecting half of the vessel's internal surface, characterised by a wide charred encrustation extending from the level reached by the food during the cooking process down to the lower part of the vessel's wall (Fig. 11b). The external surface is oxidised and surrounded by traces, as in experiment ID 2, which coincide with the residues related to the previous soot deposits (Fig. 10e).

Experiment ID 4 featured an incipient charring process of solid content generated during the cooking of a soup, consisting of cereal flour and water. Between the internal vessel wall and the cooked substance, a charring process was recorded in its early stage; this latter is not easily visible but was observed during the scraping of the upper solid layer of soup (Fig. $11 \mathrm{c}$ ). The dark deposit is compact with cracks; its consistency is different from the other experimental deposits, most likely due to the preserved superficial soup layer which avoided a total dehydration of the content as recorded in Experiment ID 2 (Fig. 10 f). This latter deposit featured a powdery charred encrustation with no cracks, as instead were visible in Experiment ID 4 (Fig. 11c), suggesting that the consistency of a vessel's content can influence the formation of charred deposits.

The external surface of the vessel base, in contact with the floor during the cooking phase, and internal vessel surfaces, in contact with moist contents, both remained free from soot traces (Fig. 11b).

\subsubsection{Chemical alterations}

In one case (Exp. ID 4), in a vessel used for legume soup, small depressions developed on the surface of the internal wall, precisely along the dark band of charring. These traces feature rounded and oval shapes, coarse texture, mixed closed and connected frequency, with a shallow incidence, horizontal orientation and irregular/sharp edge morphology (Fig. 8f). These alterations only appeared a few months after the final experimental cooking. During the abandonment stage, the film of carbon deposits cracked and receded, causing the detachment of the deposit from the attached superficial ceramic material. Acid components of content permeated within the ceramic through its pores and reacted chemically with the paste components. This caused an impairment of the chemical and physical ceramic bonds as they reacted with material wear in conjunction with a detachment of the superficial carbon film.

Moreover, the washing of the vessel with water highlighted the alterations produced by the combination of tribochemical mechanisms that occurred during both the cooking and washing phases. This alteration most likely left the ceramic material exposed to the chemical attachment of the food acids (Arthur, 2003; Oura et al., 1982; Purdy and Clark, 1987). 


\section{2 Archaeological use wear and residues}

\subsubsection{Abrasive wear}

Abrasive wear was identified on the external surfaces of all vessel bases, featuring recurrent patterns of distribution, which provided information regarding the degree of development of the wear processes. The traces were highly developed over the entire base surface in the form of striations, scratches, grooves, depressions, levelling of the whole area and rounding/levelling of the protruding parts.

From a macroscopic observation, all the analysed vessel bases became levelled and rounded in proximity to the protruding parts (Fig. 12a). In two cases (ID 2,11), where the base surface is characterised by a sinuous topography, there is a distinct contrast between the texture of the technological depressions, which preserve their original coarse morphology (Fig. 12b), and the levelling of the protruding parts, characterised by the rounding of the depression edges and the consequent exposure of the paste inclusions (Fig. 12c-d).

Through a more detailed observation performed using a stereo microscope, it was possible to identify recurring patterns in striations, scratches and grooves, which featured a linear shape, coarse texture, closed frequency, shallow incidence, U-shaped cross section and irregularrounded edge morphology. These alterations were distributed along the protruding parts (Fig. 12e-h) and the external edge of the vessel base (Fig. 12i-l).

In one case (ID 138) abrasive traces led to the levelling of the entire surface originally featured by a flat/sinuous topography as hypothesised by the analyses of the preserved wall surfaces (Fig. 12i; 13f).

The wear location, intensity and orientation suggest a concentration of mechanical stress and likely a repetition over time of these phenomena, producing the rounding of the protruding parts. This vessel was affected by at least two different abrasive processes. The most invasive was probably an abrasive wear caused by liquid substances, which acted as a lubricant in the tribological system, causing small matrix particles to detach during the sliding movement (Schiffer and Skibo, 1989). Levelling traces diffused all over the external base are predominant and resemble the wear observed in the experimental specimens generated by the sliding of two surfaces with a similar hardness (eg. ceramic or a mud plains). Detachment of material from the external base could also be caused by an aggressive chemical reaction stemming from the substance contained in the vessel. However, in the case of ID 138, the observed surface levelling, characterised by a flat topography, was probably due to a tribological system in the form of lubricated abrasive processes.

A further abrasive process affecting specimen ID 138, not associated with the presence of water in the tribological system, is suggested by the striations that feature a coarse texture and an irregular rounded edge morphology. 

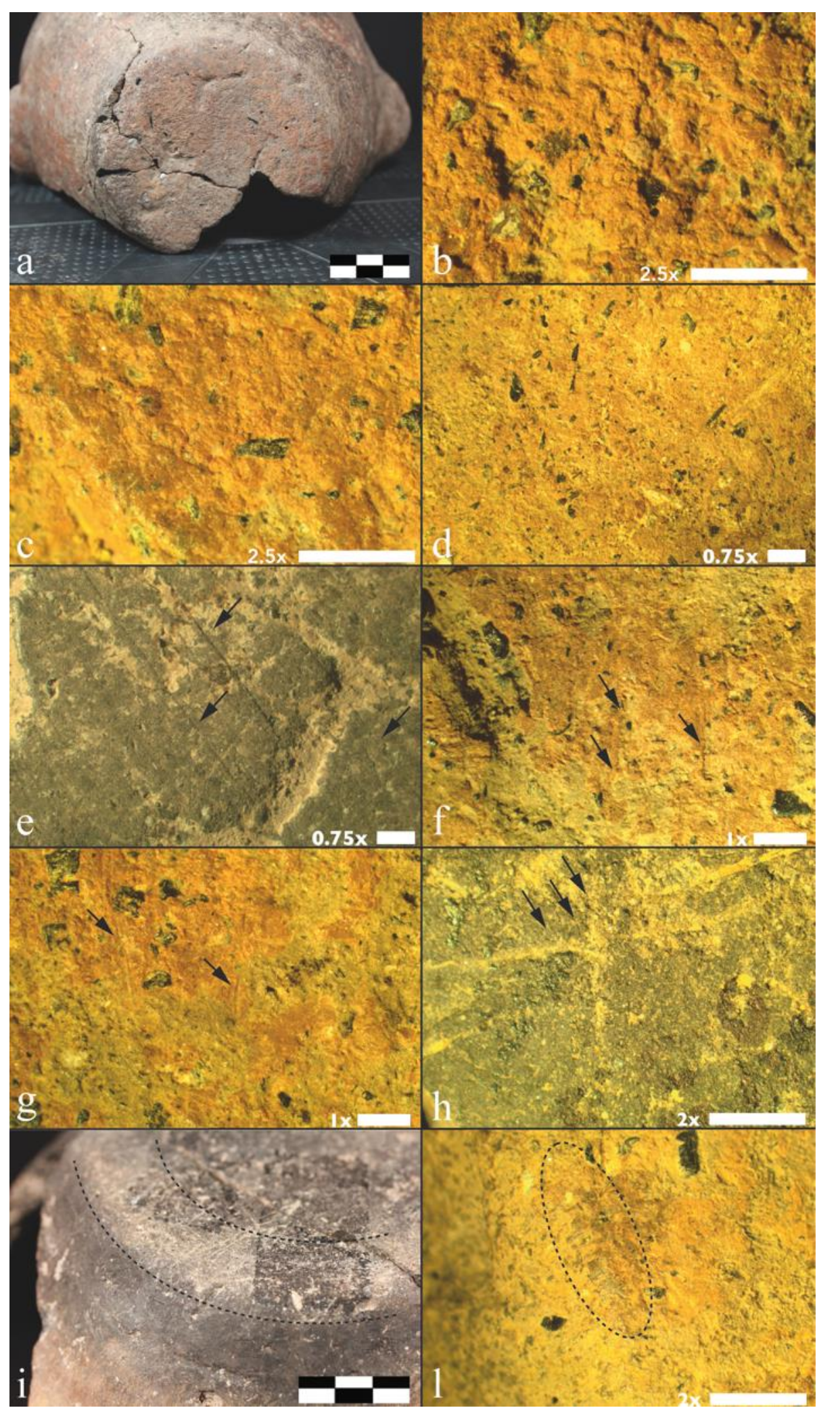

15

16

17

18

19
Figure 12 - Abrasive wear identified on archaeological ceramic vessels: a) Overview of an external base surface featuring a relevant levelling and rounding of the protruding parts (ID 2); b) Coarse morphology of technological depressions (ID 2); c) Levelling detail of the protruding parts on the external base surface (ID 2); d) Exposure of inclusions due to abrasive processes (ID 11); e) Striations along the external base surface (ID 475); f) Scratches along the external base surface (ID 2); g) Striations and scratches on the external base surface (ID 2); h) Detail of grooves on the external base surface (ID 138); i) Overview of an external base surface featuring a relevant rounding and levelling of the protruding parts (ID 138); 1) Striations and scratches on the external base edge (ID 2) (white bar in Fig. a and i equals to $1 \mathrm{~cm}$ ). 
All the analysed vessels feature evident modifications to their internal and external surfaces (Fig. 13).

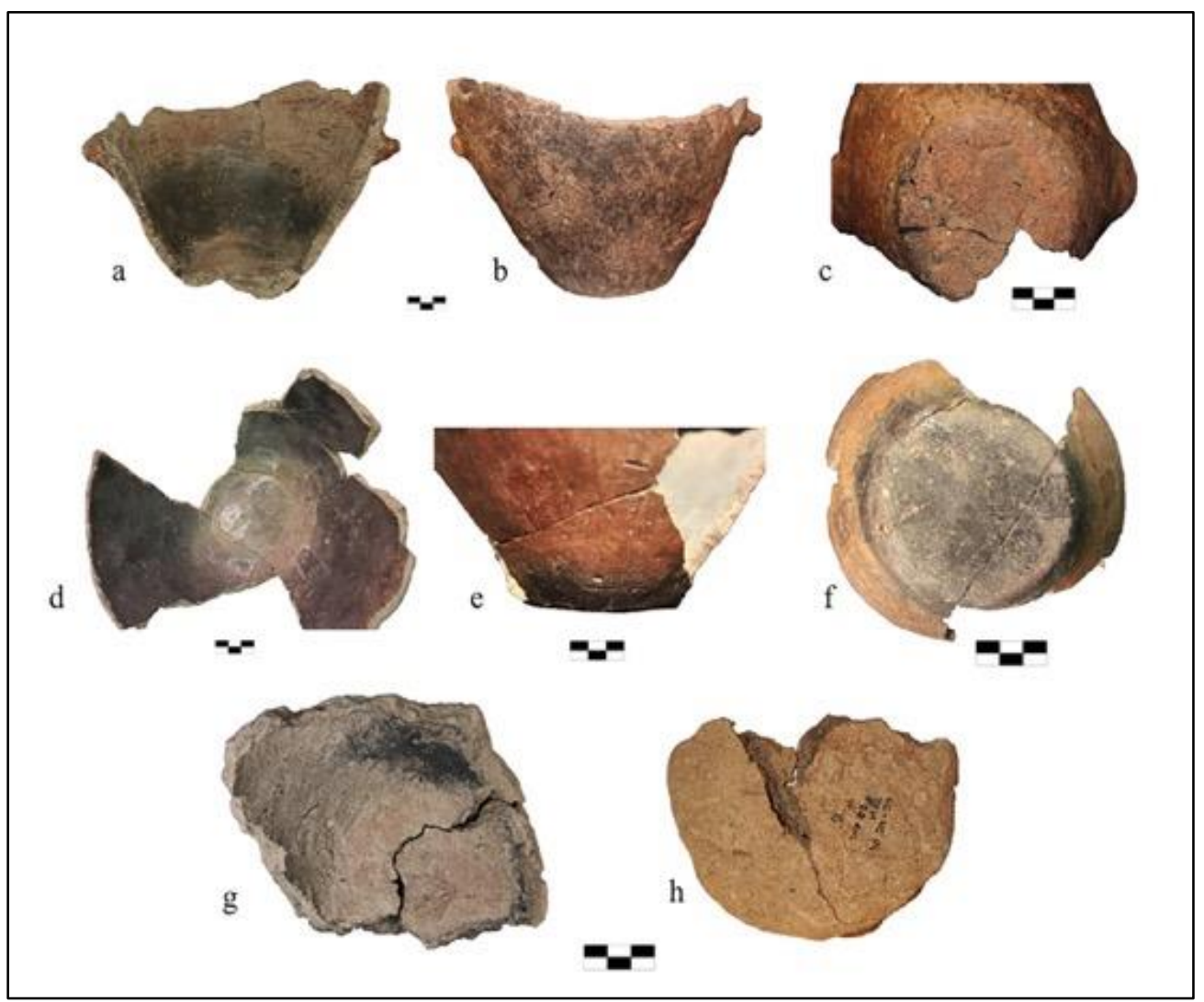

Figure 13 - Thermal alterations identified on some of the archaeological ceramic vessels analysed: a) Dark band of carbon deposit with localised charred encrustations along the lower part of the internal wall surface of ID 2; b) Soot distributed along the external wall surface of ID 2; c) External base surface of ID 2; d) Carbon deposit extending along the full internal surface of ID 138, featuring localised charred encrustations; e) Soot localised along the articulation wall/base of ID 138; f) External base surface of ID 138; g) Carbon deposit with charred encrustation localised along the articulation wall/base of ID $11 ; \mathrm{h}$ ) External base surface of ID 11.

These alterations, such as dark bands or concentrations of charred encrustations (Fig. 14b), are distributed on the internal surfaces along the vertical middle section or the middle-lower walls, coinciding in the latter case with the base/wall articulation. (Fig. 13a, d, g).

10 Along the internal and external vessel surfaces, thermal alterations present themselves in two 11 main variations, distinguished by patterns of localisation and extension.

12 In three cases (ID 2, 138 and 11) the internal residue occurs with a precise location (Fig. 13a, $13 \mathrm{~d}, \mathrm{~g}$ ). In almost all of the vessels the wear is located along the base/wall articulation. In particular, one vessel (ID 2) shows a residue concentration along the whole band, coinciding with the middle/lower part of the wall (Fig. 13a). In all of the analysed specimens, charred encrustations were found in relation to the dark area of the internal surface (Fig. 13). Only in one case did the carbon deposit extend uniformly along all internal wall and base surfaces (Fig. 13 d); specific localised carbonised residues were sampled for compositional analyses (see 4.2.3).

20 The internal and external base surfaces of all the vessels analysed appear oxidised (Fig. 13c, 21 13h), with the exception of only one vessel (ID 138) (Fig. 13f), which featured an internal carbon deposit extending over all of the internal vessel surfaces. 
The external soot traces featuring different localisation patterns are visible in two cases: in the first case (ID 2) the trace is fleeting, irregular and distributed along the external surface area, which coincides with the location of the internal carbon deposit; the base, however, is oxidised (Fig. 13b). In the second case (ID 138) the soot is distributed along the external base up to the wall/base articulation, coinciding with the area of the internal vessel surface which is covered by an extended carbon deposit (Fig. 13-f).
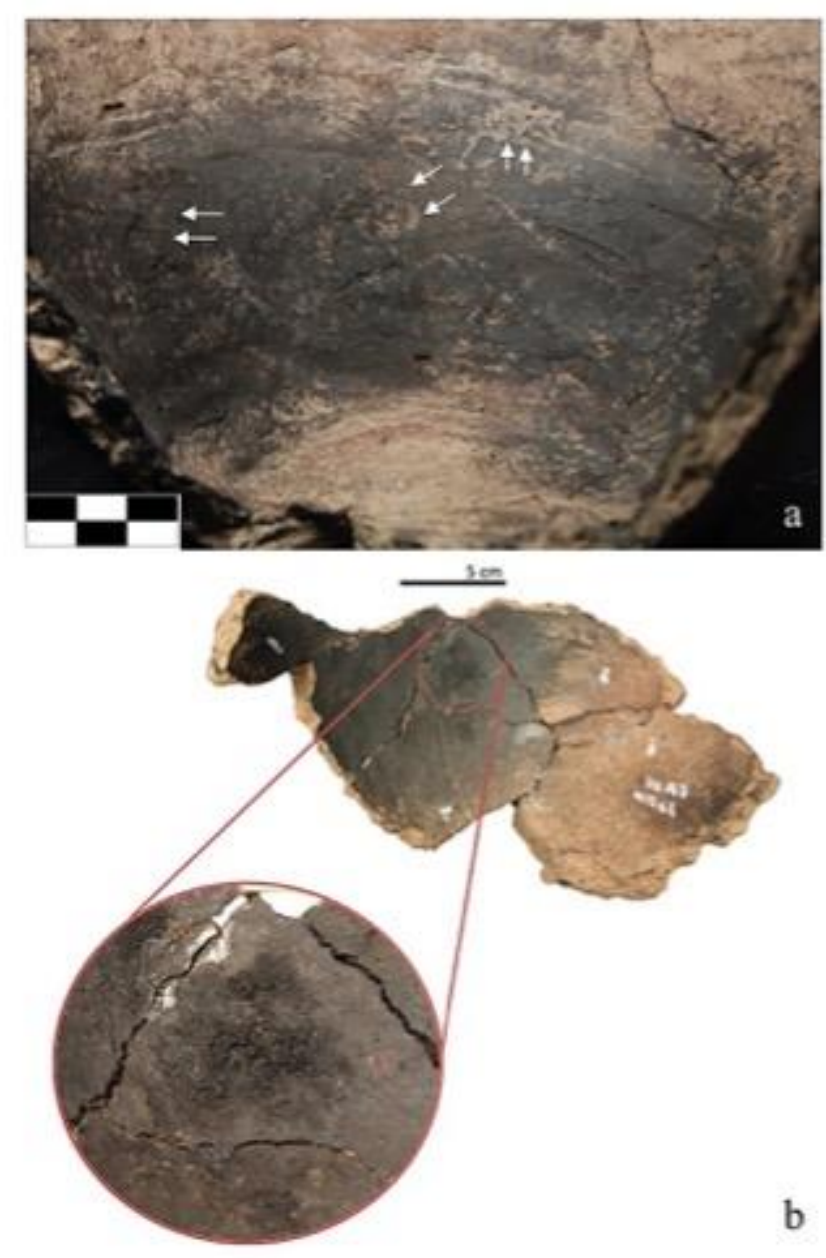

Figure 14 - Chemical alterations and charred encrustations identified in archaeological ceramic vessels: a) Depressions and charred encrustations on the internal wall surface of ID 2; b) Charred encrustation along the internal wall surface of ID 475.

\subsubsection{Chemical wear}

Only in one case, ID 2, was chemical wear identified. Evident depressions occurred along the internal wall surface, corresponding to the horizontal dark band and in association with charred encrustrations. These alterations occur with a rounded and oval shape, coarse texture, closed frequency, mixed incidence, mixed orientation and irregular sharp edge morphology (Fig. 14a). The features of these traces, along with their localisation on the middle portion of the internal wall, an area usually not affected by abrasive processes, suggest a chemical nature to the wear process, leading to the corrosion of the surface at various stages. According to the experimental results, the characteristics of the identified depressions suggest that the vessel was

subject to a continuous chemical stress, which led to wear away some of the clay component of the paste, determining a visible in a granular detachment.

\subsubsection{FTIR analysis of archaeological charred encrustations}

Small samples taken of excavation earth, clean ceramic and carbonaceous residues were spectroscopically analysed in the same conditions as archaeological spelt and barley grains gave similar spectroscopic patterns. For example, Fig. 15 compares the spectral behaviour of ground (a), ceramic material (b) and carbonaceous residue (c) sampled by the archaeological vessel ID 504. In all spectra an intense band at $1038 \mathrm{~cm}^{-1}$ can be assigned to the Si-O stretching mode of the silicate component of the clay, while the less intense peaks at 911 and $471 \mathrm{~cm}^{-1}$, attributed to $\mathrm{Al}_{2} \mathrm{OH}$ and $\mathrm{Si}-\mathrm{O}-\mathrm{Al}$ bending modes respectively, suggest traces of kaolinite (Madejová, 2003). The peak at $530 \mathrm{~cm}-1$ suggests the presence of iron oxide traces (Bikiaris et al., 2000). The absorption band at $911 \mathrm{~cm}-1$ is absent in the ceramic material spectrum (b), suggesting a different provenance of the starting clay used in the production or a process of purification. 
In the figure 15, FTIR spectra of archaeological barley and spelt grains collected from archaeological contexts are also reported ( $\mathrm{d}$ and e respectively). Barley and spelt grains comprise 70-90\% carbohydrates, including total carbohydrates (e.g., sugars) and structural ones (cellulose), $5-25 \%$ proteins and $1-10 \%$ lipids.

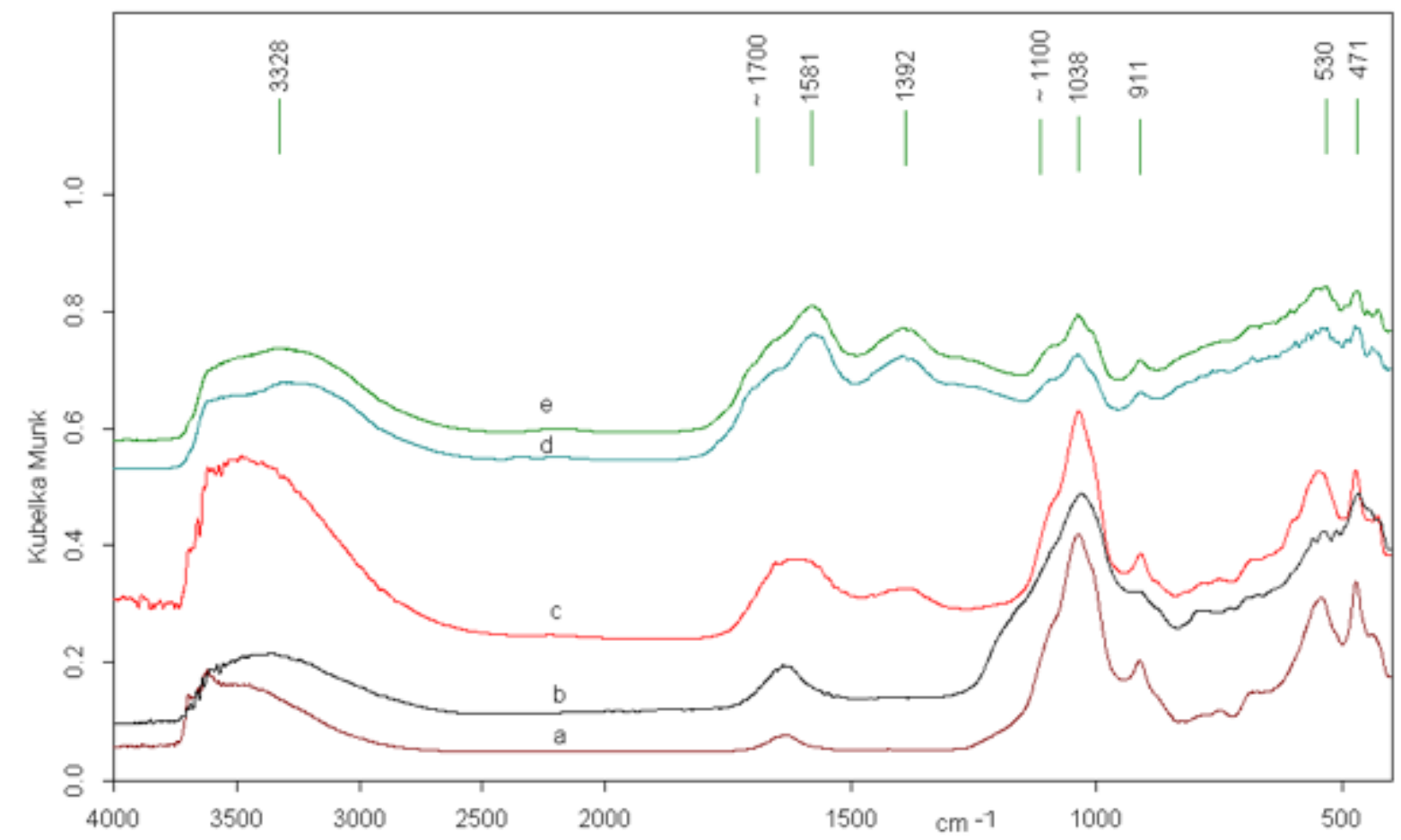

Figure 15. Comparison of DRIFT spectra of ground (a) ceramic of sample ID 504 (b), residue of sample ID 504 (c). archaeological barley (d) and archaeological spelt (e).

The spectra of archaeological spelt and barley are similar to those of cereal grains available in literature (Gholizadeh et al., 2014 and references therein). Therefore, the assignment reported in the mentioned paper can be adopted: bands at $~ 3300$ and $\sim 1600 \mathrm{~cm}^{-1}$ belong to $\mathrm{O}-\mathrm{H}$ stretching and $\mathrm{H}-\mathrm{O}-\mathrm{H}$ bending modes respectively. The latter band shows weak shoulders at 1700 and $\sim 1100 \mathrm{~cm}^{-1}$ respectively, attributable to $\mathrm{C}=\mathrm{O}$ and $\mathrm{C}-\mathrm{O}$ stretching modes of carbohydrates (Cozzolino et al., 2015; Gholizadeh et al., 2014, Ibrahim et al., 2006). The peak at $1390 \mathrm{~cm}-1$ is tentatively attributed to aromatic components (Oudemans et al., 2007).

All heretofore mentioned bands are detected in the spectrum of the residue, even if partially overlapped by the infrared active vibrations due to the ceramic material.

\section{Discussion}

The application of an integrated study comprising use wear analysis, spectroscopic analysis and experimental archaeology made it possible to understand the processes causing significant alterations to selected pottery vessels from Copper Age settlements of the modern Rome area. The analysis of these alterations and their development suggest the exploitation of the vessels for cooking activities. Although archaeological literature on pottery function has explored all of the activities connected with use, a systematic application of empirical use wear analyses is not yet diffused. By treating a vessel as a tool (Braun, 1983) it is possible to investigate the activities in which it was involved and the traces these left; in this perspective, a systematic integration of use wear and residues analysis can represent a methodological framework with 
great potential. The case study presented here is an explanatory example highlighting that, as shown by ethnoarchaeological cases, use wear on archaeological ceramic has still not been entirely explored (Lopez Varela et al., 2002). This contribution suggests that alterations usually attributed to casual events or post-depositional modifications are actually related to a combination of mechanical and chemical processes. These processes generate specific wear through various tribological mechanisms, which affect the ceramic surfaces and involve liquids or damaging acids. Comparing the forms of wear identified on the archaeological vessels, there is a clearly identifiable difference between wear affecting the external vessel base and wear which affects the more preserved surfaces of vessels that were probably used for storage or for dry activities related to food.

The recurrence of evident dark encrustations connected with varying extended powder deposits consistently localised on the vessels' internal surfaces suggests their use in activities involving heat. In a domestic context, cooking is the primary activity connected with fire, yet casual burning can produce fire alterations; in the same way, post-depositional modifications can lead to surface degradation that is often similar to intentional use wear. Traditional use wear studies stressed that wear localisation must be the first variable to consider for a functional interpretation of ceramic material (Lugli and Vidale, 1996; Skibo, 1992; Vieugué, 2014). However, trace morphology is able to identify the related mechanisms and interpret the use activities in which a vessel was involved. Although the sample selected for this article is limited, the recurrence of some of the most diffused traces connected with use facilitated an experimental approach to the investigation of the associated domestic activities. Moreover, this concentrated study contributed to a greater knowledge regarding cooking techniques utilised by peoples settled in the modern Rome area during the Copper Age.

The entire sample of analysed vessels features fire exposure as the cause of most recurrent alterations. Localisation of internal and external carbon deposits, characterised by evident internal charred encrustations, suggest that the vessels were used to cook. Various evidence suggests the way in which pots were used: the most preserved vessels show an internal carbon deposit along the wall, while the internal and external base are free from any colour alterations. This should indicate a placement of the pots laterally to the fire. Along with the thermal principles extant in ethnoarchaeological literature (Skibo, 1992), the experimental program documented the relationship between a vessel's proximity to the fireplace and resulting specific fire alterations. The recurrent localisation of charring and powder carbon deposits along the middle-lower part of the vessel, excluding the base, suggest that the vessel reached high temperatures for an extended time, leading to charring. These pots received heat from a lateral/downwards direction, suggesting that the vessels were most likely placed higher than the fire level. Recurrence of internal carbonisation traces could be caused by repeated accidental charring events or, more probably, by partial cleaning events, which left residues of the processed substance inside the pot, depending also on the diligence of the people involved in the cleaning activity (Arthur, 2002). The positioning of the vessels laterally to the fire is also suggested by evident tribological wear on the external vessel base. Recurrent levelled surfaces were favoured by continued exposure of the vessel to liquid and semi-liquid components of food, absorbed through the pores. Liquids, such as water used to clean the vessels or for cooking, often moistened the external base. Here, the concentrated abrasive wear begins when the vessel is put on the floor or near the fire, leading to abrasive processes in the presence of liquid. Traces were different, however, for vessels of the same shape but involved in domestic dry activities. The observed traces, according to the principles of abrasive processes (Schiffer and Skibo, 1989) and a dedicated experimental use wear framework, hint towards processes involving a moisturised ceramic surface sliding against a surface with a similar (medium) hardness; this would support the hypothesis that one of the vessels, unearthed from a domestic 
oven (Anzidei et al., 2007) in the site of Osteria del Curato, was exploited for food processing within that specific structure until it was discarded.

Just one vessel (ID 138) from the considered samples exhibited different traces of fire exposure, suggesting a position on top of the fire. Internal and external fire traces (the vessel is the only one which also features carbonisation traces along the internal vessel base) indicate that the heat came from the bottom and affected the external base of the vessel; the localisation of the external soot hints towards a position of the vessel either directly on top of the coals or on a specific cooking structure used to support the vessel. Moreover, the wear localised on the external vessel base and affecting the surface, leading to the obliteration of the previous black deposit, suggests that the last active use of the vessel (e.g. storing) did not involve contact with fire; this latter trace was alterated by an invasive abrasive wear (Beck et al., 2002). The consistency of charred residues, according to experimental protocols focusing on dry and wet cooking techniques, led to an interpretation of these vessels as having been used for wet cooking activities. This techique, which aims to produce soups or stews containing liquid or semi-liquid food that can be prepared in a variety of ways, involves placing pots near the fire for an indirect processing of the meal.

Moreover, the physical features of charred encrustations point towards a use of these vessels to process cereal soups or meals possibly containing cereal flour, as supported by FTIR results. The processing of foods vulnerable to fermentation, as those based on cereals can be, could lead to the development of specific wear localised on the internal wall, represented by depressions caused by chemical damage. These alterations occur earlier than the final carbon deposit event, which clearly covered a wide part of the area affected by chemical wear. This indicates that the vessel was used periodically for the processing of acidic foods, which led to a damaging of the ceramic paste. These traces form a strong parallel with the traces recorded by Arthur (2002) during his ethnoarchaeological studies in Ethiopia on the indicators of socioeconomic status found on pottery vessels.

On the basis of spectroscopic analyses, allowed to identify spelt and barley as archaeological residues highlighting the support of this technique in the study of organic residues alone, we cannot exclude that these vessels might have also been used to cook meat or other vegetablebased meals. Moreover, the consistency of the experimental encrustation suggests that the preparation of almost solid meals was easily affected by carbonisation of dense products, obtained by the mixing of rough flour with water. Other archaeological evidence, such as the palaeobotanical remains of cereals in various areas of the domestic contexts and diffused use wear on lithic tools, attributable to cereal cutting, suggest an impact of cereals in the domestic economy, in which the vessels investigated were repeatedly used as pots to process foods utilising wet cooking techniques and indirect heat exposure.

\section{Conclusions}

The application of an integrated approach, comprising use wear analyses, spectroscopic analyses and experimental archaeology, facilitated exploration of the actual function of specific prehistoric ceramic vessels used as cooking pots. Experimental protocols were instrumental in monitoring the invasive charred encrustations and the overlapping wear mechanisms associated with specific activities related to food processing; this approach produced a specific comparative collection of experimental wear as a useful resource for future food processing studies. While the results of the experiments confirmed some of the patterns of wear distribution and development observed in previous ethnoarchaeological studies, the experiments performed during this research also highlighted how charring can vary depending on the meal processed (e.g. whole cereals or raw flours).

The preliminary investigation of charred encrustations through spectroscopic analysis avoided irredeemably altering archaeological vessels suitable for future residues investigations. This 
methodology was applied for hypothesising the organic nature of the processed substances and support an interpretation of the analysed vessels as cooking pots.

For these reasons, future research should focus on a multianalytical approach to the investigation of ceramic fuction in order to provide new data regarding culinary habits and, more broadly, vessel and ceramic tool use in daily life or ritual activities.

\section{Acknowledgements}

This work was supported by the European funding program H2020-MSCA-IF-702493. The authors would like to thank the Soprintendenza Speciale per i Beni Archeologici di Roma for granting access to the archaeological materials subject of this study. Special thanks go to Dr. Jenny Adams and Prof. Cristina Lemorini for the fruitful discussions regarding the application of the tribological approach for the investigation of use wear on ceramic materials and thanks to the anonymous reviewers providing useful comments and suggestions to improve and strength the article.

\section{References}

Adams J. L., 1986. A use wear Analysis Comparing Handstones Used to Process Hides and Corn. M.A. Thesis, Department of Anthropology, University of Colorado.

Adams, J. L. 2014. Ground stone use-wear analysis: a review of terminology and experimental methods. J. Archaeol. Sci. 48, 129-138.

Adams, J., Delgado S., Debreuil L., Hamon C., Plisson H., Risch R., 2009. Functional analysis of macro-lithic artefacts: a focus on working surfaces, in Sternke F., Eigeland L., Costa L.J. (Eds.), Non-flint raw material use in Prehistory. Old prejudices and new directions. BAR (I.S.), Oxford, pp. 43-66.

Anzidei, A.P., Carboni, G., 2011. La facies del Gaudo nel territorio di Roma nel quadro delle manifestazioni culturali eneolitiche del versante tirrenico, in: Aurino, P. (Ed.), Tra le rocce nascoste agli dei. Incontro di studi in ricordo di Giancarlo Bailo Modesti, Napoli, pp. 309-321.

Anzidei, A.P., Carboni, G., Castagna, M.A., Celant, A., Cianca, M., Egidi, R., Favorito, S., Funiciello, R., Giordano, G., Malvone, M., Tagliacozzo, A., 2007. L'abitato eneolitico di Osteria del Curato-Via Cinquefrondi: nuovi dati sulle facies archeologiche di Laterza e Ortucchio nel territorio di Roma, in: Atti IIPP XLI, Firenze, pp. 477-508.

Anzidei, A.P., Carboni, G., Carboni, L., Catalano, P., Celant, A., Cereghino, R., Cerilli, E., Guerrini, S, Lemorini, C., Mieli, G., Musco, S., Rambelli, C., Pizzuti, F., 2011. Il Gaudo a Sud del Tevere: abitati e necropoli dall'area romana, in: Atti IIPP XLIII, L'Età del Rame in Italia. Firenze, pp. 309-321.

Arthur, J. W., 2002. Pottery Use-Alteration as an Indicator of Socioeconomic Status: An Ethnoarchaeological Study of the Gamo of Ethiopia. J. Archaeol. Method. Th. 9, 331-355.

Arthur, J. W., 2003. Brewing beer: status, wealth, and ceramic use alteration among the Gamo of south-western Ethiopia. World Archaeology 34, 516-528.

Banducci, L., 2014. Function and Use of Roman Pottery: A Quantitative Method for Assessing Use-Wear. Journal of Mediterranean Archaeology 27, 187-210.

Barnett, W, Hoopes J., 1995. The Emergence of Pottery, Smithsonian Institution Press, Washington DC.

Beck, M.E., Skibo J. M., Hally D.J., Yang P., 2002. Sample Selection for Ceramic Use-alteration Analysis: the Effects of Abrasion on Soot. J. Archaeol. Sci. 29, 1-15.

Bikiaris D., Daniilia Sister, Sotiropoulou S, Katsimbiri O., Pavlidou E., Moutsatsou AP, Chryssoulakis Y, 2000. Ochre-differentiation through micro-Raman and micro-FTIR 
spectroscopies: application on wall paintings at Meteora and Mount Athos, Greece. Spectrochim. Acta A 56, 13-18.

3 Bradfield, W. 1931. Cameron Creek Village: A site in the Mimbres area in Grant Count, New

4 Mexico. Monographs of the School of American Research 1, Santa Fe.

5 Bray, A., 1982. Mimbres black on white Melanie or Wedgewood? A ceramic use- wear analysis.

6 Kiva 47, 133-149.

7 Braun, J. A., Willis R., W. Barth, M., Neumann G.K., 1967. The Gentleman Farm Site, LaSalle

8 County, Illinois, Illinois State Museum, Report of Investigations 12.

9 Braun, D. 1983. Pots as Tools, in: Archaeological Hammers and Theories, New York: Academic

10 Press, 107-134.

11 Bruce, A. J.,1989. Use wear Analysis of White Mountain Redwares at Grassoppher Pueblo,

12 Arizona, Kiva, 54, 353-360.

13 Carboni, G., Anzidei, A.P., 2013. L'eneolitico recente e finale del Lazio centro-meridionale: una puntualizzazione sullo sviluppo e la durata di alcuni aspetti culturali sulla base delle più recenti datazioni radiometriche, in: Cocchi Genik, D. (Ed.), Cronologia assoluta e relative dell'età del rame in Italia. Atti dell'Incontro di Studi, Università di Verona, Verona, pp. 91-118.

Chernela, J., 1969. In Praise of the Scratch: The importance of Aboriginal Abrasion on Museum Ceramic Ware. Curator: The Museum Journal, 12, 174-179.

Cozzolino, D., Degner, S., Eglinton, J.K., 2015. In situ study of water uptake by the seeds, endosperm and husk of barley using infrared spectroscopy. Spectrochim Acta A: Mol Biomol Spectrosc, 150, pp.200-206.

Craig, O. E. 2004. Organic analysis of food crusts from sites in the Schelde valley, Belgium: a preliminary evaluation. Notae Praehistoricae, 24, 209-217.

Czichos, H., 1978. Tribology: a Systems Approach to the Science and Technology of Friction, Lubrication, and Wear, Elsevier, Amsterdam.

De Garmo, G.D. 1975. Coyote Creek, Site 01: A methodological study of prehistoric pueblo population. Doctoral dissertation, Department of Anthropology, University of California, Los Angeles. University Microfilms, Ann Arbor, Michigan.

Dugay, L., 1996. Specialized pottery production on bronze age Cyprus and pottery use-wear analysis. J. Mediterr. Archaeol. 9, 167-192.

Ericson, J. E., Read, D., Burk, C., 1972. Research design: The relationships between primary functions and the physical properties of ceramic vessels and their implications for ceramic distributions on an archaeological site. Anthropology UCLA 3, 84-95.

Fenner, G. J., 1977. Flare-rimmed bowls: A sub-type of Mimbres Classic Black-on-white? The Kiva 43, 129-141.

Follieri, M., Magri, D., Narcisi, B., 1993. Palaeoenvironmental investigations on long sediment cores from volcanic lakes of Lazio (central Italy) - an overview, in: Negendank, J.F.W., Zolitschka, B. (Eds.), Palaeolimnology of European Maar Lakes. Lecture Notes in Earth Sciences, Springer Verlag, Heidelberg, Germania, pp. 95-107.

Forte, V., 2015. Tecnologia e funzione nella produzione ceramica eneolitica del territorio di Roma: casi studio, problemi e potenzialità della ricerca. PhD thesis in Archaeology, XXVI Ciclo Sapienza Universita di Roma. Pubblicazioni Aperte Digitali della Sapienza. http://hdl.handle.net/10805/2653.

Forte, V., Medeghini, L., 2017. A preliminary Study of Ceramic pastes in the Copper Age Pottery Production of the Rome Area. Archaeol. Anthropol. Sci. 9, 209-222.

Gholizadeh, H., Naserian, A.A., Xin, H., Valizadeh, R., Tahmasbi, A.M., Yu, P., 2014. Detecting carbohydrate molecular structural makeup in different types of cereal grains and different cultivars within each type of grain grown in semi-arid area using FTIR spectroscopy with uni- and multi-variate molecular spectral analyses. Anim. Feed Sci. Tech. 194, 136-144. 
Griffith, D.M., 1978. Use-marks on historic ceramics: A preliminary study. Hist. Archaeol. 12, 68-81.

Hally, D. J., 1983. Use alteration of pottery vessel surfaces. An important source of evidence in the identification of vessel function. N. Am. Archeol. 4, 3-26.

5 Hally, D. J., 1986. The Identification of Vessel Function: a case study from northwest Georgia. American Antiquity 51, 267-295.

Hayden, B., 1979. Lithic Use-Wear Analysis. Academic Press, New York.

8 Ibrahim, M., Alaam, M., El-Haes, H., Jalbout, A.F., de Leon, A., 2006. Analysis of the structure

Kobajashi, M., 1994. Use alteration analysis of Kalinga pottery: interior carbon deposits of cooking pots, in: Longacre, W.A., Skibo, J. (Eds.), Kalinga etnoarchaeology. Expanding archaeological method and theory. Smithsonian Institution Press, Washington D.C., pp.129168.

Lemorini, C. 2007. L'abitato eneolitico di osteria del curato- via cinquefrondi (Roma): caratterizzazione funzionale per mezzo dell'analisi delle tracce d'uso dell'industria in pietra scheggiata, in: Atti IIPP XLI, Firenze, pp. 627-631.

Lemorini, C., Nunziante Cesaro, S., Celant, A., Nucara, A., Maselli, P., Skakun, N., Abbo, S., Gopher, A., 2014, The function of prehistoric lithic tools: a combined study of use-wear analysis and ftir microspectroscopy. results and open problems, in: Lemorini, C., Nunziante Cesaro, S. (Eds.) An Integration of the Use-Wear and Residue Analysis for the Identification of the Function of Archaeological Stone Tools, BAR (I.S.), Oxford, pp. 63-76.

Lepère, C., 2014. Experimental and traceological approach for a technical interpretation of ceramic polished surfaces. J. Archaeol. Sci. 46: 144-155.

Lettieri, M., 2015. Infrared spectroscopic characterisation of residues on archaeological pottery through different spectra acquisition modes. Vibrational Spectroscopy 76, 48-54.

Lopez Varela, S.L., Van Gijn, A., Jacobs, L., 2002. De-mystifying pottery production in the Maya Lowlands: detection of traces of use-wear on pottery sherds through microscopy analysis and experimental replication. J. Archaeol. Sci. 29, 1133-1147.

Lugli, F., Vidale, M., 1996. Making and Using Ceramics: on the role of technical events in the generation of functional types. Origini XX, 351-382.

Magri, D., Follieri, M., 1992. Transitions from interglacial to glacial at Valle di Castiglione (Roma), in: Kukla, G.J., Went, E. (Eds.), Start of a Glacial, NATO ASI Series I: Global Environmental Change, Vol. 3, Springer Verlag, Berlin, Germania, pp. 23-36.

Marreiros, J.M., Gibaja-Bao, J.F., Ferreira-Bicho, N., 2015. Use-wear and Residues Analysis in Archaeology. Manuals in Archaeological Method, Theory and Technique, Springer, New York.

Madejová, J., 2003. FTIR technique in clay mineral studies. Vib. Spectrosc. 31, 1-10.

Nunziante-Cesaro, S., Lemorini, C., 2011. The function of prehistoric lithic tools: A combined study of use-wear analysis and FTIR microspectroscopy. Spectrochim. Acta Part A 86, 1-6.

Olofsson, J., 2011. Friction and wear mechanisms of ceramic surfaces. With applications to micro motors and hip joint replacement. Digital Comprehensive Summaries of Uppsala Dissertations from the Faculty of Science and Technology.

Organisation for Economic Cooperation and Development, 1969. Glossary of Terms and Definitions in the Field of Friction, Wear and Lubrication. Tribology. Research Group on Wear of Engineering Materials, Organisation for Economic Co-operation and Development (OCED), Paris.

Oudemans, T.F.M., Boon, J.J., Botto, R.E., 2007. FTIR and Solid- state ICP/MAS NMR Spectroscopy of charred and non- charred solid organic residues preserved in Roman Iron Age vessels from the Netherlands. Archaeometry 49, 571-294.

Oura, E., Suomalainen, H., and Viskari, R., 1982. Breadmaking, in: Rose, A.H. (Ed.), Fermented 
Foods, Vol. 7, Economic Microbiology, Academic Press, London, pp. 88-147.

2 Perino, G., 1966. The Banks Village Ste, Crittenden, County, Arkansas. Memoir 4. Missouri Archaeological Society.

Purdy, B.A., Clark, D.E., 1987. Weathering of Inorganic Materials: Dating and Other Applications. Advances in Archaeological Method and Theory 11, 211-253.

6 Radivojević, M., Rehren, T., Pernicka, E., Šljivar, D., Brauns, M., Borić, D., 2010. On the origins

Rice, P.M., 1987. Pottery Analysis. A Sourcebook. The University of Chicago Press, Chicago.

Rice, P.M., 1999. On the Origins of Pottery. Journal of Archaeological Method and Theory 6, $1-54$.

Robb, J., 2007. The Early Mediterranean Village. Agency, Material Culture, and Social Change in Neolithic Italy. Cambridge University Press.

Roffet-Salque, M., Dunne J., Altoft, D.T., Casanova, E., Cramp, L.G.E., Smyth, J., Whelton, H.L., Evershed, R.P., 2017. From the inside out: Upscaling organic residue analyses of archaeological ceramics. J. Archaeol. Sci.Reports 16, 627-640.

Rohn, A.H., 1971. Mug House. Mesa Verde National Park, Colorado. National Park Service. Archaeological Research Series 7D, Washington.

Sassaman, K., 1993. Early Pottery in the Southeast: Tradition and Innovation in Cooking Technology. Tuscaloosa: University of Alabama Press.

Schiffer, M.B., Skibo, J., 1989. A provisional Theory of Ceramic Abrasion, American Anthropologist 91, 101-115.

Semenov, S. A., 1964. Prehistoric Technology. An Experimental Study of the Oldest Tools and Artefacts from Traces of Manufacture and Wear, London.

Shillito, L.M., Almond, M. J., Wicks, K., Marshall, L.R., Matthews W., 2009. The use of FT-IR as a creening techniquefor organic residue analysis of archaeological samples. Spectrochim. Acta A 72, 120-125

Skibo, J. M., 1992. Pottery Function. A Use-alteration Perspective. Springer, New York.

Skibo, J.M., 2013. Understanding pottery function. Springer, New York.

Skibo, J.M., 2015. Pottery Use-Alteration Analysis, in: Marreiros, J.M., Gibaja Bao, J.F., Ferreira Bicho, N. (Eds.), Use-Wear and Residue Analysis in Archaeology. Springer, New York, pp. 189-198.

Skibo, J., Schiffer, M., 1987. The effects of water on processes of ceramic abrasion. J. Archaeol. Sci. 14, 83-96.

Skibo, J.M., Butts, T.C., Schiffer, M.B., 1997, Ceramic surface treatment and abrasion resistance: an experimental study. J. Archaeol. Sci. 24, 311-317.

Tringham, R., Cooper, G., Odell, G., Voytek, B., Whitman, A., 1974. Experimentation in the formation of edge damage: A new approach to lithic analysis. J. Field Archaeol. 1, 171-196.

Valamoti, S.M., 2011. Ground cereal food preparations from Greece: the prehistory and modern survival of traditional Mediterranean 'fast foods'. Archaeol. Anthropol. Sci. 3, 19-39.

Van Gijn, A., Haufman, 2008. Were they used as tools? An exploratory functional study of abraded potsherds from two pre-colonial sites on the island of Guadeloupe, northern Lesser Antilles. Carribb. J. Sci. 44, 21-35.

Vaughan, P., 1985. Use-wear Analysis of flaked stone tools. University of Arizona Press, Tucson.

Vieugué, J., 2014. Use-wear analysis of prehistoric pottery: methodological contributions from the study of the earliest ceramic vessels in Bulgaria (6100-5500 BC). J. Archaeol. Sci. 41, 622630.

Vieugué, J., 2015. What were the recycled potsherds used for? Use-wear analysis of Early Neolithic ceramic tools from Bulgaria (6100-5600 cal. BC). J. Archaeol. Sci. 58, 89-102.

Vieugué, J., Mirabaud, S., Regert, M., 2008. Contribution méthodologique à l'analyse 
1 fonctionnelle des céramiques d'un habitat néolithique: l'exemple de Kovacevo (6200-5500 av.

2 J.-C.). Rev. d'archéométrie 32, 99-114.

3 Vitelli, K., 1989. Were pots first made for foods? Doubts from Franchthi. World Archaeology, 4 20, 17-29.

5 Vuković, J. B., 2009. Non-abrasive pottery surface attrition: Blagotin evidence. J. Serbian 6 Archaeol. Soc. 25, 25-35.

7 Vuković, J. B., 2011. Early Neolithic Pottery from Blagotin, Central Serbia: A Use-Alteration 8 Analysis, in Kraub, R. (Ed.), Beginnings - New Research in the Appearance of the Neolithic 9 between Northwest Anatolia and the Carpathian Basin. Papers of the International Workshop 10 8th - 9th April 2009. IMPRESS Druckerei Halbritter KG, Halle/Saale, pp. 205-211. 